University of Louisville

ThinkIR: The University of Louisville's Institutional Repository

Electronic Theses and Dissertations

$5-2017$

\title{
Colorectal cancer FIT screening in the hope vi population of Jefferson County, Kentucky.
}

Jeffrey D. Stone

University of Louisville

Follow this and additional works at: https://ir.library.louisville.edu/etd

Part of the Community Health Commons, Geographic Information Sciences Commons, Other Public Health Commons, and the Public Health Education and Promotion Commons

\section{Recommended Citation}

Stone, Jeffrey D., "Colorectal cancer FIT screening in the hope vi population of Jefferson County, Kentucky." (2017). Electronic Theses and Dissertations. Paper 2709.

https://doi.org/10.18297/etd/2709

This Master's Thesis is brought to you for free and open access by ThinkIR: The University of Louisville's Institutional Repository. It has been accepted for inclusion in Electronic Theses and Dissertations by an authorized administrator of ThinkIR: The University of Louisville's Institutional Repository. This title appears here courtesy of the author, who has retained all other copyrights. For more information, please contact thinkir@louisville.edu. 


\title{
COLORECTAL CANCER FIT SCREENING IN THE HOPE VI POPULATION OF JEFFERSON COUNTY, KENTUCKY
}

\author{
By \\ Jeffrey D. Stone \\ B.S. University of Louisville, 2012

\begin{abstract}
A Thesis
Submitted to the Faculty of the

College of Arts and Sciences of the University of Louisville

in Partial Fulfillment of the Requirements

for the Degree of
\end{abstract} \\ Master of Science \\ in Applied Geography \\ Department of Geography and Geosciences \\ University of Louisville \\ Louisville, Kentucky
}

May 2017 
Copyright @ 2017 by Jeffrey Darren Stone

All rights reserved 



\title{
COLORECTAL CANCER FIT SCREENING IN THE HOPE VI POPULATION OF JEFFERSON COUNTY, KENTUCKY
}

\author{
By \\ Jeffrey D. Stone \\ B.S. University of Louisville, 2012
}

A Thesis Approved on

April 14, 2017

by the following Thesis Committee:

\begin{tabular}{c} 
Thesis Director \\
Dr. Carol Hanchette \\
\hline $\begin{array}{c}\text { Second Committee Member } \\
\text { Dr. Margath Walker }\end{array}$ \\
\hline Third Committee Member \\
Dr. Gerard Barber
\end{tabular}




\section{DEDICATION}

This thesis is dedicated to my son Zachary who has given me the motivation and strength to continue my education, and to my wife Ramona who made it all possible and who never stopped believing in me. 


\section{ACKNOWLEDGMENTS}

I would like to thank my professor, Dr. Carol Hanchette, for her invaluable feedback and patience, and to my committee members, Dr. Margath Walker and Dr. Gerard 'Rod' Barber, for their guidance and assistance over the years. 


\title{
ABSTRACT \\ COLORECTAL CANCER FIT SCREENING IN THE HOPE VI POPULATION OF JEFFERSON COUNTY, KENTUCKY
}

\author{
Jeffrey D. Stone
}

April 14, 2017

Using pre-post survey data collected from 209 randomly selected African American people from the population of former residents of Clarksdale and Sheppard Square public housing areas, this study explores the relationship between individual characteristics and colorectal cancer screening behavior, measured by the uptake of the Fecal Immunochemical Test (FIT) and by prior colorectal screening, while controlling for neighborhood factors and geographic proximity to healthcare facilities. This particular public housing population is of interest because of their relocation from the downtown area, where healthcare facilities are within walking distances, to other public housing units either in large apartment complexes or scattered throughout the county, or to units on the rental market. The framework used for this study is the Andersen's Healthcare Services Utilization Model, where variables are measured at individual and at census tract level. Analyses include descriptive and multivariate statistical techniques. Data are presented in tables, graphs, and choropleth maps. 
TABLE OF CONTENTS

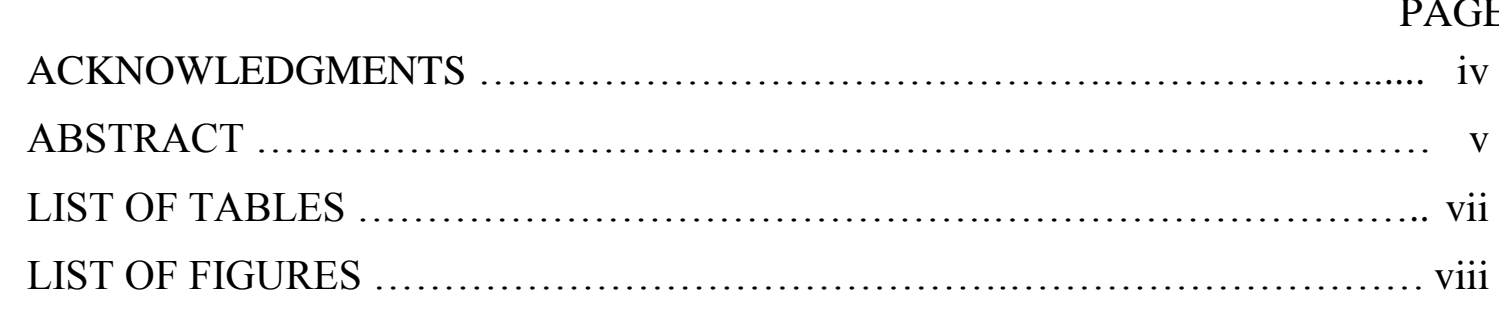

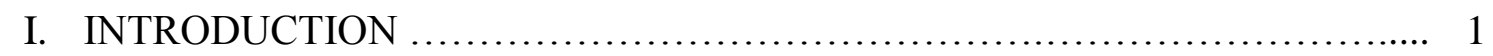

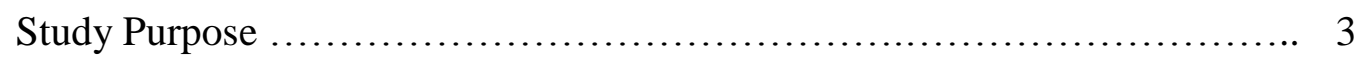

II. LITERATURE REVIEW ................................................. 4

Research Hypothesis .................................................. 9

Theoretical Framework ................................................. 10

FIT Sensitivity and Specificity ....................................... 12

III. DATA AND METHODS _............................................... 13

Project Description ................................................... 13

Research Design ..................................................... 13

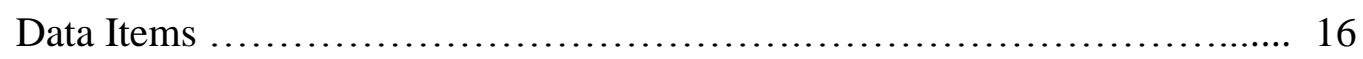

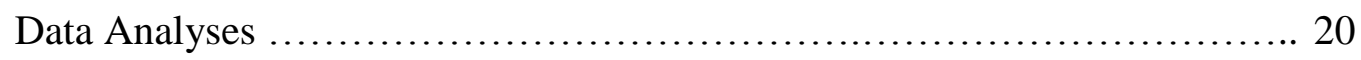

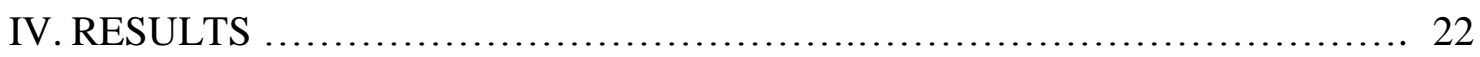

Univariate Analyses .................................................. 22

Bivariate Analyses .................................................... 26

Individual-Level Factors by CRC Screening Behavior .................... 26

Dependent Variable: FIT Return Status ...................................... 26

Dependent Variable: Prior CRC Screening ............................... 33

Neighborhood-Level Factors by CRC Screening Behavior .................... 38

Multivariate Analyses ................................................... 42

V. DISCUSSION AND CONCLUSIONS _................................. 49

Limitations ........................................................... 52

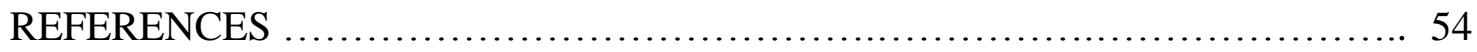

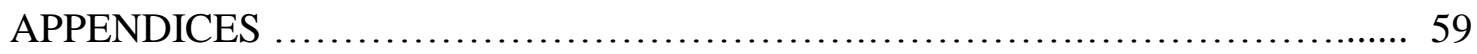

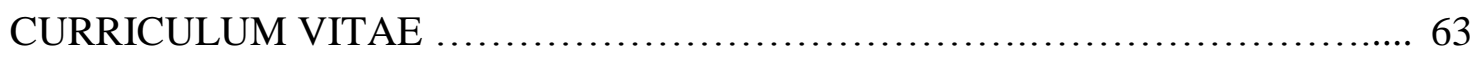




\section{LIST OF TABLES}

TABLE

PAGE

1. Colorectal Incidence and Mortality Rates per 100,000 Persons ................. 2

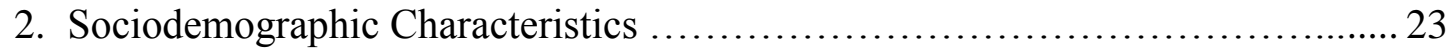

3. Sociodemographic Characteristics by FIT Return Status ...................... 27

4. FIT Kit Return by Sociodemographic Characteristics ....................... 28

5. FIT Kit Return by Discrete Sociodemographic Characteristics ................. 29

6. Prior CRC Screening Status by Sociodemographic Characteristics .............. 34

7. Prior CRC Screening by Discrete Sociodemographic Characteristics ........... 36

8. Prior CRC Screening by Sociodemographic Numeric Characteristics ............ 37

9. Descriptive Statistics for Socioeconomic Indicators at Census Tract Level ....... 39

10. Logistic Regression: Predicting FIT Uptake/Return ......................... 43

11. Logistic Regression: Predicting Prior CRC Screening ....................... 44

12. Logistic Regression: Predicting FIT Return: Age-Adjusted Results ............. 45

13. Logistic Regression: Predicting Prior CRC Screening Age-Adjusted Results ... 46

A1. Selected CRC Studies ................................................... 59 


\section{LIST OF FIGURES}

FIGURE

PAGE

1. Colorectal Cancer Age-Adjusted Incidence and Mortality Rates ................ 2

2. Original Andersen's Healthcare Utilization Model $\ldots \ldots \ldots \ldots \ldots \ldots \ldots \ldots \ldots \ldots \ldots$

3. Context of Thesis Research ......................................... 13

4. Sample vs. Eligible Population........................................ 15

5. Application of Andersen's Model to the HOPE VI CRC FIT Screening ......... 18

6. Distribution of the HOPE VI Participants in the CRC FIT Screening ........... 24

7. HOPE VI Participants' Proximity to Healthcare Facilities $\ldots \ldots \ldots \ldots \ldots \ldots \ldots \ldots . \ldots 25$

8. Choropleth Map of FIT Kit Returns .................................. 31

9. Choropleth Map of Reactive FIT Kits ................................ 32

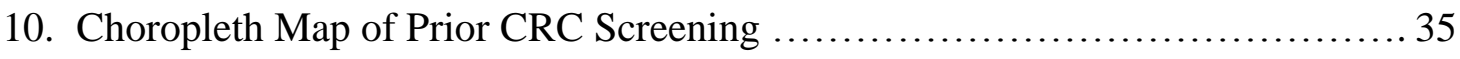

11. Histogram of Proximity to Healthcare Facilities (miles) .................... 41

12. Participants with Perceived Fair/Poor Health $\ldots \ldots \ldots \ldots \ldots \ldots \ldots \ldots \ldots \ldots \ldots \ldots . \ldots 7$

13. Perceived Fair/Poor Health by Proximity to Healthcare Facilities .............. 48

A2. FIT Kit, UK Reply Envelope, \$20 Incentive- Kroger Gift Card ............... 62 


\section{CHAPTER I \\ INTRODUCTION}

According to the Centers for Disease Control and Prevention (CDC 2016), colorectal cancer (CRC) is the second most common cancer in the United States, and second leading cause of cancer mortality (Shokar et al. 2015). For 2008-2012, Kentucky had the highest age-adjusted invasive CRC incidence rate (51.4, with a confidence interval (CI) of 50.5-52.3) per 100,000 persons, compared to the national rate of 41.9 (CI: 41.8-42.0). In addition, Kentucky had the $5^{\text {th }}$ highest CRC mortality rate 18.1 (CI: 17.6-18.7), after Mississippi, Arkansas, Louisiana, and West Virginia; the U.S. CRC death rate for 2008-2012 was 15.5 (CI: 15.4-15.6).

The Kentucky Cancer Registry (KCR) data for 2016 shows that for AfricanAmericans, the 2008-2012 CRC incidence rate in Kentucky was 58.1 (CI: 54.2-62.5) as compared to the U.S. rate of 49.7 (CI: 49.4-50.1) over the same period. The age-adjusted mortality rate was $23.4(20.8-26.2)$ as compared to the national rate of 21.4 (CI: 21.221.6). Further, in Jefferson County, Kentucky, the 2008-2012 CRC age-adjusted incidence rate was 51.7 (CI: 49.5-54.0) for all races, and 60.8 (CI: 54.7-67.3) in blacks. The age-adjusted CRC mortality rate for African-Americans in Jefferson County was 22.6 (18.9-26.8) compared to the age-adjusted rate for all races of 17.2 (CI: 16.0-18.6). Data obtained from the National Cancer Institute (NCI), presented in Table 1 and in 
Figure 1, show the age-adjusted incidence rates per 100,000 people for colorectal cancer at the national (gray), state (blue), and county (red) levels.

\section{Table 1}

Colorectal Cancer Incidence and Mortality Rates per 100,000 Persons

\begin{tabular}{lcccc}
\hline $2008-2012$ & \multicolumn{2}{c}{ Incidence Rates } & \multicolumn{2}{c}{ Mortality Rates } \\
\hline & All Races & Black & All Races & Black \\
U.S.A. & 41.9 & 49.7 & 15.5 & 21.4 \\
Kentucky & 51.4 & 58.1 & 18.1 & 23.4 \\
Jefferson Co. & 51.7 & 60.8 & 17.2 & 22.6 \\
\hline
\end{tabular}

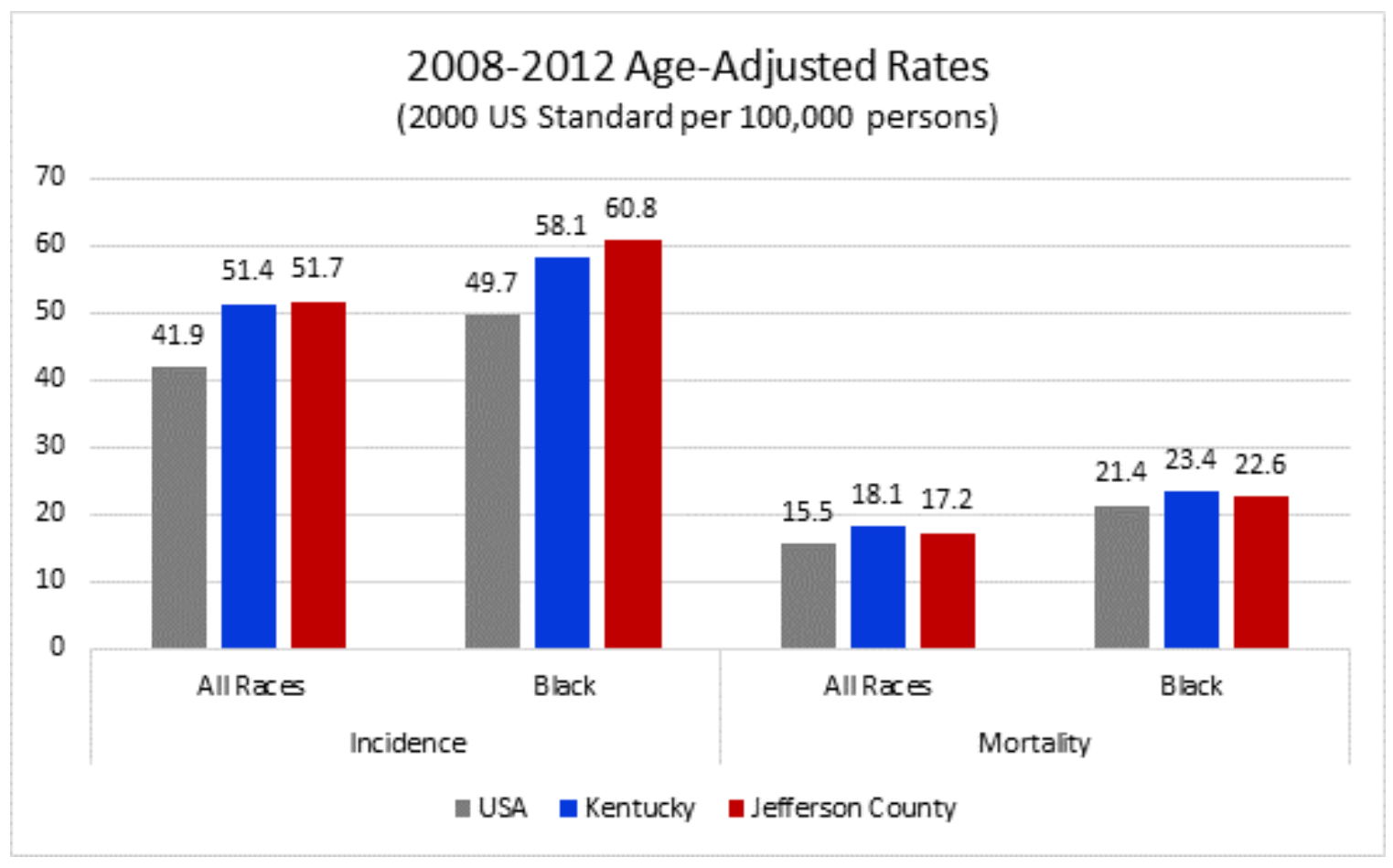

Figure 1. Colorectal Cancer Age-Adjusted Incidence and Mortality Rates 


\section{$\underline{\text { Study Purpose }}$}

This study aimed to explore the uptake of the Fecal Immunochemical Test (FIT) in a population of African Americans, of ages 45 to 75, who had very low income, which means at least below the $100 \%$ federal income level as defined by the federal poverty guidelines, and who were residents of Clarksdale or Sheppard Square public housing developments at the time they were demolished. The interest in this population and in this topic is twofold.

First, numerous studies on racial health disparities show that African American populations have higher mortality and lower survival rates (Cooper et al. 1995; Hassan et al. 2009; Laiyemo et al. 2010; Enewold et al. 2012; Beyer et al. 2016), that might be explained by differences in stage of disease at the time of diagnosis (Enewold et al. 2012), to healthcare utilization, including cancer screening (Laiyemo et al. 2010), to have access

to healthcare (Laiyemo et al. 2010; Hall, Ruth, and Giri 2012; Sabounchi, Keihanian, and Anand 2012) or to have access to the latest treatments available (Hao et al. 2009; Sineshaw, Robbins, and Jemal 2014).

Second, the residents in these two communities were relocated across Jefferson county Kentucky, when their neighborhoods were slated for redevelopment, fully demolished and rebuilt. The cancer research shows that neighborhood socioeconomic inequalities are associated with disparities in the risk for premature death among healthy adults (Doubeni, Schootman, et al. 2012), but not among the adults with poor health. Moreover, the relationship between both individual and area-level socioeconomic status and the incidence of CRC was found to be significant (Doubeni, Laiyemo, et al. 2012). 


\section{CHAPTER II}

\section{LITERATURE REVIEW}

To reduce the burden of colorectal cancer on public health, the U.S. Preventive Task Force recommends population-based screenings, including an annual high-sensitivity fecal occult blood testing, such as the FIT, which is available as an inexpensive and easy to use home kit. It is estimated that CRC screening could prevent about a third of the annual deaths; yet screening rates remain low, especially among the uninsured and underinsured populations (Shokar et al. 2015). Furthermore, the CRC mortality rate declined in the past two decades as a result of screening, but it was in primarily white populations, and racial disparities persist (Green and Coronado 2014).

The more recent national CRC screening rates in whites are about $62 \%$ as compared to $55 \%$ in African Americans and 47\% in Hispanics (Sineshaw, Robbins, and Jemal 2014). Lower rates of screening are generally associated with lower income, lower education, and minority social status (Steele et al. 2008; Doubeni et al. 2009; Hassan et al. 2009; Paskett et al. 2011; Cole, Jackson, and Doescher 2012; Hines and Markossian 2012; Jemal et al. 2015). Studies of disparities across geographic regions showed that rural areas have significantly lower screening rates than urban areas (McLafferty and Wang 2009; Cole, Jackson, and Doescher 2012; Monson et al. 2014; Wheeler et al. 2014; Daly et al. 2015). These differences are explained by factors specific to rural populations, including lower socioeconomic status, lack of insurance and spatial access or distance to the nearest 
healthcare facility. However, the rural-urban differences in late-stage diagnosis show that not all urban populations fare better than rural populations.

Urban low-income populations form "clusters of urban disadvantage" with significantly poorer health than other urban or rural populations (McLafferty and Wang 2009). One study found that the odds of urban African Americans for late stage diagnosis were $40 \%$ greater than the odds of whites in rural Georgia (Hines and Markossian 2012). Other studies found that areas with higher poverty and geographically remote areas have lower CRC screening rates (Cress et al. 2006; Espey et al. 2007; McLafferty and Wang 2009; Paskett et al. 2011; Cole, Jackson, and Doescher 2012; Perdue et al. 2014; Towne et al. 2014; Towne, Smith, and Ory 2014; Faruque et al. 2015). Within the rural areas the lowest screening rates were in the most remote areas, while in urban areas the lowest screening rates were in the census tracts with high proportions of minority and low socioeconomic status populations, hence the higher incidence of late-stage diagnosis and mortality rates found in these disadvantaged groups.

As stated earlier, many studies on racial health disparities show that African American populations have higher mortality and lower survival rates (Cooper et al. 1995; Hassan et al. 2009; Laiyemo et al. 2010; Enewold et al. 2012; Beyer et al. 2016). Some suggest that the disproportionately higher CRC incidence and mortality rates in African Americans compared to whites might be a result of differences in healthcare utilization (Laiyemo et al. 2010) rather than to colorectal cancer susceptibility; others pose that ethnicity itself "is a factor for disparate outcomes in colorectal cancer" (Hassan et al. 2009). Differential access to healthcare was explained by disparities in screening rates 
(Theuer et al. 2006; Hall, Ruth, and Giri 2012; Brenner et al. 2015) which remain significantly lower in African Americans than in whites.

The access to healthcare was defined by other in terms of quality of care, and specifically access to latest treatments available for CRC. One study shows that the disparities in mortality rates between older blacks diagnosed with metastatic CRC and their white counterparts were specifically related to the differences in access to the latest available treatments (Sineshaw, Robbins, and Jemal 2014). They claim that African Americans "have not equally benefitted from the introduction and dissemination of new treatments." (Sineshaw, Robbins, and Jemal 2014). However, another study (Sabounchi, Keihanian, and Anand 2012) found "no racial difference in the treatment outcome of CRC"; the "patients with similar treatment had similar outcomes". They concluded that the "severity of disease at presentation and the outcome of treatment [were] not dependent on race." (Sabounchi, Keihanian, and Anand 2012).

Furthermore, the literature on health disparities shows that the neighborhood of residence matters. The "individuals residing in poorer communities with lower access to medical care did not experience the reduction in $\mathrm{CRC}$ incidence rates seen in more affluent communities" (Hao et al. 2009). Hao and colleagues claim that disparities across neighborhoods with different median incomes could be explained by the barriers to healthcare access, such as lack of health insurance and lack of a regular healthcare provider.

A different set of studies focused on the development of practical models for colorectal cancer screening and patient navigation for populations known to be at higher 
risk for CRC mortality or CRC late stage diagnosis (Bolen, Adams, and Shenson 2007; Escoffery et al. 2015; Shokar et al. 2015; Beyer et al. 2016; Brenner et al. 2016).

The overall conclusion of these studies (Table A1) is that there are significant disparities across geographic regions of the United States, and across race and socioeconomic groups. One common recommendation across the studies is to increase screening in highly urbanized areas where there is a high proportion of minority in poverty, and to tailor communications (Myers et al. 2007) for better outreach. Future studies should use individual level socioeconomic data, number of physicians, and geographic access to healthcare, to explain regional variations (Espey et al. 2007; Schenck et al. 2009; Perdue et al. 2014).

One of the most vulnerable urban populations is that of families eligible for housing subsidies; the majority of these are racial and/or income minorities. Housing, along with income and race, are common indicators used in health disparity research (Tawk et al. 2015). Public housing residents and other inadequately housed individuals, are at higher risk to be under-screened for this disease. The health behaviors research focused on low-income residents housed in larger public housing developments and in scattered or market rental housing is scarce.

The different housing subsidies are due to a Housing and Urban Development (HUD) federal program of urban development that provides federal support to local housing authorities to redevelop dilapidated public housing projects into mixed income communities. Since 1996, HUD has awarded four Housing Opportunities for People Everywhere (HOPE VI) grants to the local Louisville Metro Housing Authority (LMHA); in 1996, Cotter \& Lang Homes; in 2002, Clarksdale I; in 2003, Clarksdale II; and in 2010, 
Sheppard Square. One of the main criticisms of the HOPE VI program is that residents lose their easy access to critical services, such as transportation and healthcare.

The HOPE VI program has somewhat controversial reviews and diverse outcomes across the nation; it was recently replaced with the Choice Neighborhoods program. According to the HUD's website, the new program, like HOPE VI, aims to rebuild communities by addressing long-term disinvestment through community-driven strategies. The HOPE VI grants directly influenced the lives of about 13,000 residents and their families; over 90\% of these people were African Americans, about $80 \%$ were females, about half were ages 18 or below, and about $13 \%$ were ages 45 or older. The researchers at the University of Kentucky, stated in the protocol submitted to the Institutional Review Board, that during March 2016, there were 1,656 African American former HOPE VI residents, ages 45-75 in the LMHA's Tracking System; 1,343 (81.1\%) of the 1,656 residents were women. The tracking system is an administrative database, internal to LMHA, with highly sensitive information about each HOPE VI resident; it is not available to the public.

The former Clarksdale (now Liberty Green) and Sheppard Square residents were relocated during 2004 and 2011, respectively, from the downtown area to various locations across Jefferson County, Kentucky. Both Clarksdale and Sheppard Square areas are located near the medical campus of the University of Louisville (UofL); thus, at relocation, the majority of the residents lost their easy access to healthcare facilities located downtown. Therefore, this population is especially attractive to sociologists and public health researchers who want to learn of the types of effects relocation had on people's lives. Could relocation to mixed-income neighborhoods have made an impact on 
individual employment, social, or health behaviors such as CRC screening? While some research discusses the potential effects of the HOPE VI relocation on individual employment and social behavior (Curley 2010), little research discusses its potential impact on health behaviors (Pollack et al. 2014; Hayward et al. 2015), even though it is well documented that poor health is "an even bigger problem for HOPE VI families than lack of employment (Manjarrez et al. 2007).

Using a focus group methodology, Hayward and colleagues found that, before demolition, public housing developments were unhealthy physical environments that limited residents' health and wellbeing, that contributed to social isolation of its residents. They suggest that "increased neighborhood social capital could improve health" and recommend use of housing policies to improve environmental health conditions (Pollack et al. 2014; Hayward et al. 2015). Pollack and colleagues conducted a natural experiment to compare residents in scattered housing with residents in larger housing developments on their social network's perceived health and health behaviors. They found no differences in the perception of major health problems in one's social network by place of residents. However, participants who resided in scattered public housing were more likely to state that their neighbors exercise more than the participants who resided in larger public housing developments (Pollack et al. 2014; Hayward et al. 2015).

\section{$\underline{\text { Research Hypothesis }}$}

The main hypothesis of this thesis research is that the socioeconomic level of the area of residence does not affect individual health seeking behavior, such as accessing and 
utilization of healthcare services, after controlling for individual characteristics.

Specifically, the research questions are:

1. What are the individual characteristics that make a difference in individual FIT uptake?

2. What are the individual characteristics associated with prior CRC screening behavior?

3. What are the neighborhood factors that make a difference in a person's CRC screening behavior?

a. Are HOPE VI residents who relocated to mixed-income communities more likely to accept the FIT screening than the residents who reside in primarily African-American low-income communities?

b. Are HOPE VI residents who relocated to mixed-income communities more likely to have had prior CRC screening than the residents who reside in primarily African-American low-income communities?

4. Is there a relationship between proximity to healthcare facilities and the prior utilization of CRC screening services among urban African Americans, current or former HOPE VI public housing residents?

\section{Theoretical Framework}

The Andersen's Behavioral Model of Health Utilization (Andersen 1995) is the theoretical framework used for this study. Andersen developed this theory about two decades ago, attempting to describe and understand the factors that influence individual utilization of healthcare services (Figure 2). 


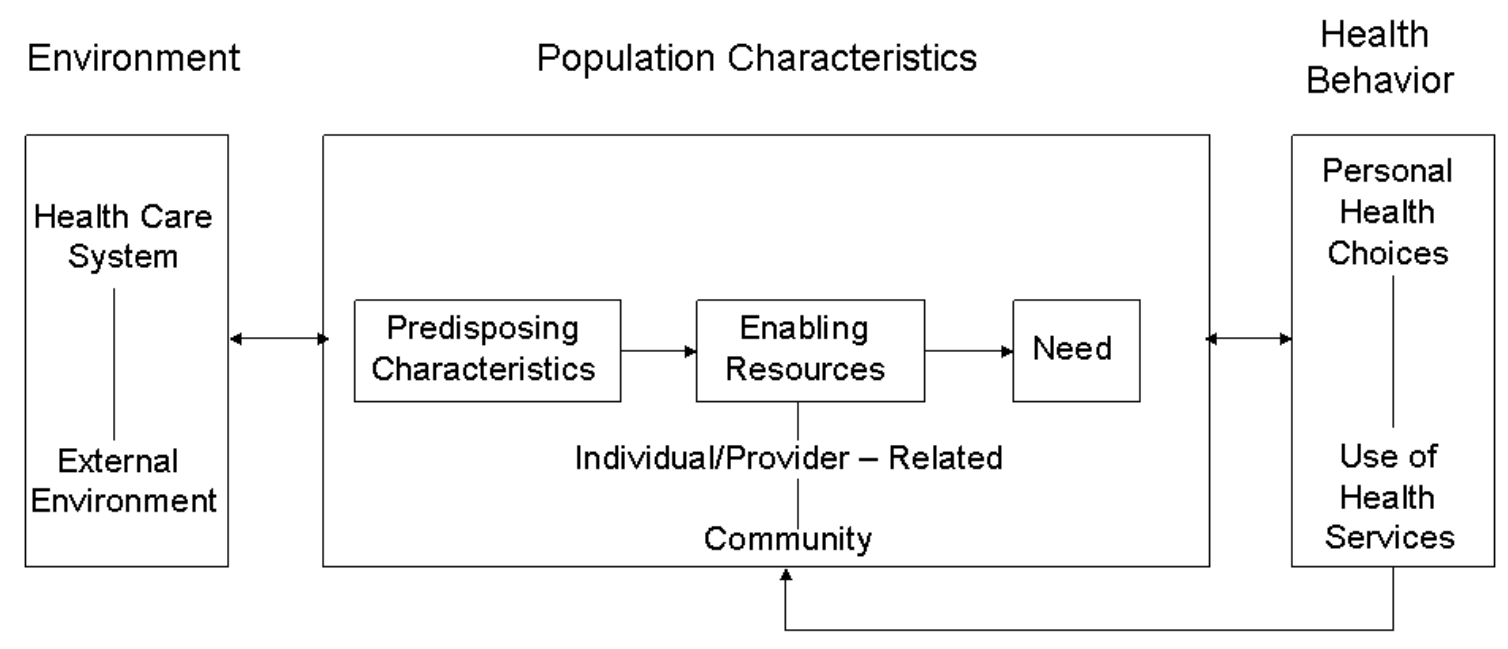

Figure 2. Original Andersen's Healthcare Utilization Model

Andersen's model combines both individual and community level indicators of health behavior, placed in a broader social context, attempting to explain the determinants of individual healthcare utilization behavior. Over the years, public health researchers have used Andersen's conceptual framework to develop healthcare utilization models that were focused on a specific disease (i.e., cancer, HIV/AIDS) or vulnerable population (i.e., homeless). The original Andersen Model of healthcare utilization was later revised to include health outcomes and healthcare satisfaction.

Andersen's models include feedback loops to show that healthcare utilization depends on both individual and contextual factors, and that ultimately, healthcare-seeking behavior has an impact on the individual health outcomes. Specifically, Andersen's models suggest that individual healthcare-seeking behavior is determined by a person's predisposing characteristics (i.e., gender, race, characteristics that are not modifiable), by the person's resources (i.e., health insurance, physical access to care), and by his/her perceived or evaluated (i.e., diagnosis) need for healthcare. Nevertheless, individuals belong to a larger context, which has an impact on the resources available to them (i.e., 
healthcare system). Health behavior includes both personal health practices and the use of health services, strongly associated with individual health outcomes. Health outcomes include the persons' perceived and evaluated health status, and consumer satisfaction.

\section{$\underline{\text { FIT Sensitivity and Specificity }}$}

A comparison study of the FIT with an older test, Guaiac-based fecal occult blood test (g-FOBT), showed that the FIT had a greater sensitivity for detection of the colorectal cancer than the g-FOBT (Oort et al. 2010). Specifically, FIT detected $87.1 \%$ of the invasive cancers as compared to $74.2 \%$ detected by the $\mathrm{g}$-FOBT ( $=.002)$; detected $35.6 \%$ of the advanced adenomas as compared to $18 \%$ detected using the g-FOBT $(p<.001)$. FIT screening sensitivity, the ability to correctly identify those with the disease, was $40.5 \%$ as compared to $23 \%$ for $\mathrm{g}$-FOBT $(\mathrm{p}<.001)$. However, the FIT screening specificity, or the ability to correctly identify those without the disease, was lower (91\%) than that of g-FOBT (95.7\%). 


\section{CHAPTER III}

\section{DATA AND METHODS}

\section{Project Description}

This thesis is a segment of a pilot survey research project conducted by a group of health behavior researchers from the Rural Cancer Prevention Center (RCPC) at the University

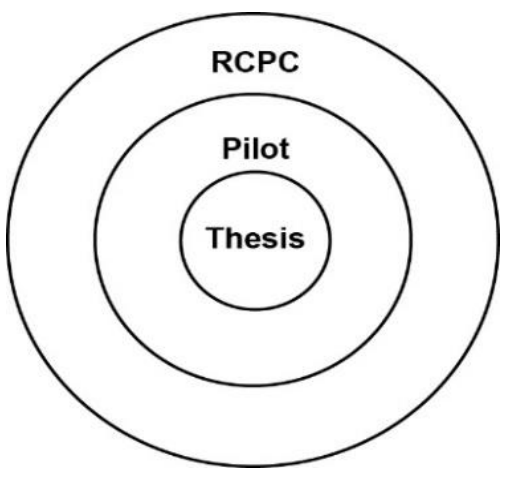

Figure 3. Context of Thesis Research of Kentucky, funded by the grant number 5U48DP005014-03 received from the Center for Disease Control and Prevention. The RCPC team designed a communitybased pilot research study (Figure 3) to compare the uptake of CRC screening FIT

kits among rural Appalachian white residents to urban low-income African Americans.

However, the thesis study is using only the data collected from the urban low-income African American group. The study area is Jefferson County, Kentucky.

\section{$\underline{\text { Research Design }}$}

This is a quasi-experimental study with a pre-post design, including both PRE (kit distribution) and POST (follow-up) surveys. Because a team of public health researchers 
at the University of Kentucky collected the pre-post surveys as part of a larger research study, the data are considered "secondary" or "existing" data for the purposes of this thesis research study.

The population of interest for this thesis study is the former residents of Clarksdale and Sheppard Square public housing areas of Jefferson County, Kentucky. From a population of 356 African-Americans of ages $45-75$, the UK team selected a simple random sample of 200 individuals and invited them to participate in the colorectal cancer screening and navigation community-based research study. LMHA approved the study and informed the residents about the opportunity for colorectal cancer screenings; they were asked to call a local number to schedule an appointment for the PRE survey and to receive the FIT kit.

The sample of participants in this study was randomly selected from the population of former Clarksdale and Sheppard Square HOPE VI public housing residents of Jefferson County, Kentucky, who were ages 45 through 75 as of July 1, 2016. The LMHA provided access to the tracking system specifically developed for the HOPE VI program. The population file was downloaded and opened in IBM SPSS 23. Next, all individuals younger than 45 and older than 75 years of age were filtered out and deleted from the population file, yielding a total of 356 people between the ages of 45 and 75 . Using SPSS, a random sample of 200 individuals was selected from these 356 individuals (Figure 5). If a selected person refused to participate, could not be found or was deceased, another resident was selected randomly from the population. Of the randomly extracted sample of 200 residents, 18 (4\%) declined to participate, and 29 (14.5\%) could not be 
located in spite of multiple attempts. These 47 people $(23.5 \%)$ were replaced with the "next in line" persons from the remaining pool.

The final sample included 200 African American public housing residents of Jefferson County, Kentucky, plus 9 family members who were either ages 45-75 or had an immediate family member diagnosed with colorectal cancer. All of the recruited people were African-Americans residents of public housing units, most of them located in the most economically distressed census tracts of Jefferson County, Kentucky (as of July-December 2016). Note that, to be eligible for public housing subsidies individuals have to meet the very low income criteria as defined by the federal income and poverty guidelines. The study eligibility criteria were, a) race (being African American), AND b) age (being between 45 and 75 years old), OR c) having a first-degree relative with a CRC diagnosis, regardless of age.

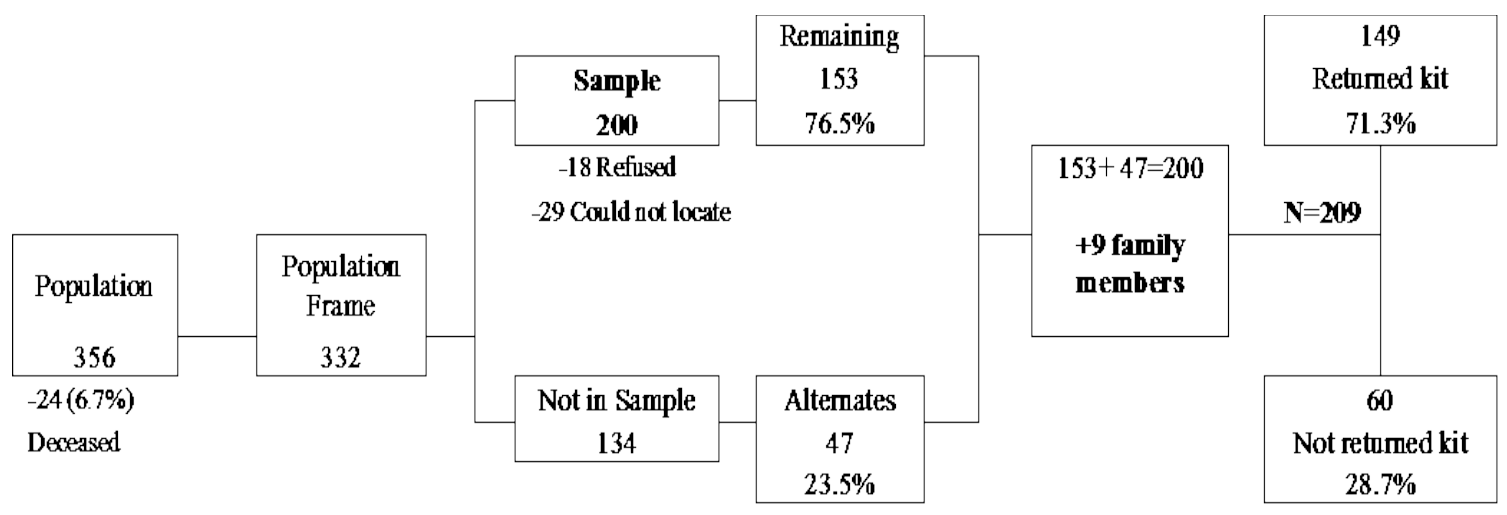

Figure 4. Sample vs. Eligible Population

Recruiting efforts included phone calls and home visits using the information available in the tracking system at LMHA. In addition, LMHA conducted three mailings, at six-week intervals. The letters explained that the University of Kentucky was enrolling participants in the study, that a person would go to their homes to conduct a brief survey 
and to provide the FIT kit to screen for CRC, and that they would receive a gift card as an incentive to participate in the study. The UK interviewer was trained to describe how to use the FIT kit and prepare the mailing, and to explain the steps of the entire process.

\section{$\underline{\text { Data Items }}$}

The PRE survey, completed in person at the time of kit distribution, included questions about health and health-related behaviors (i.e., health screening experience, eating habits, physical activity, etc.), along with sociodemographic questions. Participants used a pre-stamped envelope to mail their FIT kit to UK for analysis. Once results were

available, a second home visit was conducted to inform them of the result and to complete a brief follow-up survey about their FIT screening experience. All participants received research incentives. They received a \$20 Kroger gift card at the time of the PRE survey, and a second $\$ 20$ Kroger gift card at the time of the POST survey. The IRB at UK and at UofL approved this thesis research study.

The dependent variable is individual screening behavior (yes/no), a proxy variable for healthcare utilization. In this study, there are two variables that measure screening behavior:

i. return of the FIT kit (yes/no)

ii. prior colorectal cancer screening (yes/no)

It is noteworthy that the prior screening was conducted independent of this study, and the return of the kit is not expected to be associated with transportation or income, considering that participants were asked to return the kit by mail using a pre-stamped envelope. The independent variables were measured at two different levels: individual and 
community (census tract) level data. The individual level data items available from the pre-post surveys:

a) PRE survey: individual socio-demographics, general health questions, family history of cancer, health beliefs (perceived fatalism scale), health behaviors (smoking, alcohol use, physical activity, prior CRC screening);

b) POST-survey: experience with the use of FIT, timeline, best and worst thing about using FIT, intent to use FIT annually, intent to schedule a colonoscopy, intent to recommend to others;

c) residential address at the time of relocation and at the time of the CRC screening (reported as choropleth maps, to protect respondents' privacy).

The community data items are available at census tract level from the 2010 U.S. Census and the 5-year American Community Survey; the census tract level data was downloaded from the U.S. Census website (Census 2010) and includes measures such as the percentage of minority population, median household income, educational attainment, percentage of people living in poverty, percentage of people using public transportation. The locations of the healthcare facilities in Jefferson County, Kentucky were available in the Louisville/ Jefferson County Information Consortium (aka LOJIC), the geographic information system for the Louisville Metro area. For each resident, the distances to all healthcare sites were computed in ArcGIS. Then, a "proximity" variable was computed using the shortest distance on street networks to a healthcare site for each resident.

Using the Andersen's conceptual model, all of the data items (collected with the surveys, from the U.S. Census, and from LOJIC) were organized in a conceptual framework. Figure 5 shows the variables included in the Andersen's model under: 
(1) Environment (census tract level variables), (2) Population characteristics: a)

predisposing (age, gender), b) enabling (insurance, regular provider, education, income, housing, etc.), and c) need (perceived health status); and (3) Individual health practices (smoking, alcohol use, exercise, diet) are hypothesized to predict the (4) individual health behavior measured by prior CRC screening, and the uptake of FIT.

\begin{tabular}{|c|c|c|c|c|c|}
\hline & \multicolumn{3}{|c|}{ Population Characteristics } & \multirow{2}{*}{$\begin{array}{l}\text { Health } \\
\text { Practices }\end{array}$} & \multirow{2}{*}{$\begin{array}{l}\text { Health } \\
\text { Behavior }\end{array}$} \\
\hline Environment & Predisposing & Enabling & Need & & \\
\hline $\begin{array}{l}\text { Proximity to care } \\
\text { Poverty rates } \\
\text { Median income } \\
\text { Transportation }\end{array}$ & $\begin{array}{l}\text { Age } \\
\text { Gender } \\
\text { Family History }\end{array}$ & $\begin{array}{l}\text { Insurance } \\
\text { Education } \\
\text { Income } \\
\text { Housing } \\
\text { Marital }\end{array}$ & $\begin{array}{l}\text { Fatalism } \\
\text { Perceived Health }\end{array}$ & $\begin{array}{l}\text { Smoking } \\
\text { Alcohol } \\
\text { Diet } \\
\text { Exercise } \\
\text { Regular provider }\end{array}$ & $\begin{array}{l}\text { Prior CRC } \\
\text { Screening } \\
\text { FIT Uptake }\end{array}$ \\
\hline
\end{tabular}

Figure 5. Application of Andersen's Model to the HOPE VI CRC FIT Screening Study

The scale measuring respondent's perceived CRC fatalism has four items. The four items are: (1) "I am likely to develop colorectal cancer in my lifetime," (2) "I am worried that I will develop colorectal cancer in my lifetime," (3) "If it was meant for me to develop colorectal cancer there is nothing that I can do about it," and (4) "There is nothing I can do to reduce my risk of developing colorectal cancer." The scale has a good reliability coefficient (Cronbach's $\alpha=.726$ ); this is similar to the inter-item correlation Cronbach coefficient reported by other cancer studies (Davis et al. 2002) in low-income African American populations (Powe Fatalism Scale, $\alpha=.79$ ). Cronbach coefficient measures the reliability of a measurement scale, meaning the scales ability to yield the same results if applied multiple times. A Cronbach coefficient of 0.60 to less than 0.80 indicates that the scale has a good reliability; a coefficient of 0.80 to less than 0.90 indicates very good reliability, and a coefficient that is greater than 0.90 indicates excellent reliability. 
Survey data was collected (by the author of this paper) on paper during face-toface interviews at the home of each participant. Before completing the pre survey, the interviewer obtained informed consent for participation in the study and permission to contact and inform them of the results. Next, the pre survey was completed and the participant was instructed how to conduct the specimen collection. Finally, the kit distribution information was logged on the distribution form, and the participant was provided with a $\$ 20$ gift card after he or she signed the receipt. All study procedures were approved by the Office of Research Integrity at the University of Kentucky, and by the management staff at the LMHA. The data collection, data entry, data management, and data analyses were conducted by the author of this paper, as a part-time employee of the University of Kentucky. However, because the data was used for thesis research, the protocol received approval from by the University of Louisville's Institutional Review Board.

Each participant received a pre-stamped envelope, and a kit which included the FIT itself, two paint brushes, and two trash bags. The FIT kit has two sealed flaps (A and B, see a picture in the Appendix). Participants were instructed as follows:

1) Collect the two samples at two different points in time, within one week.

2) Use the trash bag to dispose of the toilet paper;

3) Raise flap A on the kit;

4) Dip the paint brush into the specimen;

5) Rub the paint brush onto the absorbent paper under the flap.

6) Close and seal the flap, to avoid sample contamination.

7) Write the date on the flap A; 
8) Repeat the process for the second sample, using flap B.

9) After the two samples are collected, place the kit in the pre-stamped envelope and mail the kit no later than one week from the time they collected the first sample.

\section{$\underline{\text { Data Analyses }}$}

The data was entered in the Research Electronic Data Capture System (REDCap), downloaded into SPSS, exported as a dbase file, and imported into ArcMap. The individual addresses were geocoded, counted at census tract level, and joined spatially with the socioeconomic and race data from the 2010 U.S. Census. Data analyses include basic descriptive and inferential statistics. The basic descriptive analyses include univariate and bivariate statistics.

The univariate statistics section includes counts, proportions, means, medians and standard deviations for the independent and dependent variables. For individual level data, univariate analysis was conducted by gender, race, age, current tobacco use, family history of cancer, and residential proximity to the nearest healthcare site. To test the association between returning the FIT kit and key sociodemographic and health variables, chi-square tests and t-tests were used. All variables with identified significant differences between the group of people who returned the kit and the group that did not, were entered into stepwise logistic regression models to calculate the adjusted odds ratios (OR) and their $95 \%$ CI. For census-tract level data, univariate analysis includes number and proportion of cases within each tract, number of healthcare sites within the census tract, along with choropleth maps of all census variables. 
The bivariate statistics section includes the results of chi-square tests of independence and independent t-tests for the comparisons of means. Then, logistic regression analysis was conducted to test the relationship between individual screening behavior and proximity to healthcare sites, while accounting for individual characteristics that were found significant during the bivariate analyses. The data is presented in tables, graphs, and choropleth maps. 


\section{CHAPTER IV}

\section{RESULTS}

\section{$\underline{\text { Univariate Analyses }}$}

Of the 209 African American participants, 149 (71.3\%) returned the FIT kit using the pre-stamped envelope; 42 (28.2\%) of the 149 returned kits were positive. The average age of the sample was 55.9 years $(\mathrm{SD}=7.51$ years $)$, the youngest being 37 years old and the oldest 74 years of age. As shown in Table 2, 85.6\% of participants were females, $67.2 \%$ were single, and $13.4 \%$ were married, while the remaining were divorced, separated, or widowed. The majority had at least high school level education (66.2\%), had less than $\$ 10,000$ annual household income (82.8\%), and resided in a large public housing development (69.9\%). Very few respondents were uninsured (3.3\%) or had no regular healthcare provider (4.8\%). Respondents were insured by Medicaid (58.4\%), Medicare (17.7\%), through an employer (13.4\%), or self-purchased ACA-plan (19.1\%); note that this was a multiple choice question, and the percentages can add up to more than $100 \%$ due to some of the participants having more than one insurance policy. About $80 \%$ of the participants had a BMI of 25 or greater, being overweight or obese given their height and weight, yet only $44 \%$ perceived themselves as overweight or obese. Overall, $41.6 \%$ perceived their health as fair or poor. Health behavior data shows that $48.8 \%$ were smokers and $73.7 \%$ did not drink alcohol at all during the past 30 days. 


\section{Table 2}

$\underline{\text { Sociodemographic Characteristics }(\mathrm{N}=209)}$

\begin{tabular}{|c|c|c|c|}
\hline Variable & Category & $\mathrm{N}$ & $\%$ Valid \\
\hline \multirow[t]{2}{*}{ Gender } & Male & 30 & 14.4 \\
\hline & Female & 179 & 85.6 \\
\hline \multirow[t]{6}{*}{ Age Category } & Lowest - 49 & 49 & 23.4 \\
\hline & $50-54$ & 47 & 22.5 \\
\hline & $55-59$ & 47 & 22.5 \\
\hline & $60-64$ & 41 & 19.6 \\
\hline & $65-69$ & 14 & 6.7 \\
\hline & $70-75$ & 11 & 5.3 \\
\hline \multirow[t]{4}{*}{ Current Marital Status } & Married & 29 & 13.4 \\
\hline & Divorced/Separated & 25 & 12.0 \\
\hline & Widowed & 14 & 6.8 \\
\hline & Single & 139 & 67.2 \\
\hline \multirow{5}{*}{$\begin{array}{l}\text { Highest Grade / Year of School } \\
\text { Completed }\end{array}$} & Elementary & 5 & 2.4 \\
\hline & Some high school & 65 & 31.4 \\
\hline & High school graduate/GED & 97 & 46.9 \\
\hline & Some college, technical school & 35 & 16.9 \\
\hline & College graduate & 5 & 2.4 \\
\hline \multicolumn{2}{|l|}{ Public Housing Dev. } & 146 & 69.9 \\
\hline \multirow{4}{*}{$\begin{array}{l}\text { Employment } \\
\text { (Multiple Choice) }\end{array}$} & Employed & 72 & 34.0 \\
\hline & Unable to work & 90 & 43.1 \\
\hline & Unemployed & 19 & 9.1 \\
\hline & Retired & 27 & 12.9 \\
\hline \multirow{4}{*}{$\begin{array}{l}\text { Annual Household Income } \\
\text { From All Sources }\end{array}$} & $<\$ 10,000$ & 173 & 82.8 \\
\hline & $\$ 10,000$ to $<\$ 20,000$ & 20 & 9.5 \\
\hline & $\$ 20,000$ to $<\$ 35,000$ & 11 & 5.3 \\
\hline & $\$ 35,000$ to $<\$ 75,000$ & 5 & 2.4 \\
\hline BMI calculated & Overweight or obese & 168 & 80.4 \\
\hline BMI perceived & Overweight or obese & 92 & 45.1 \\
\hline Has Health Insurance & & 202 & 96.7 \\
\hline $\begin{array}{l}\text { Has Regular Healthcare } \\
\text { Provider }\end{array}$ & & 199 & 95.2 \\
\hline Exercised (Past Week) & & 130 & 62.2 \\
\hline Smoker (past 30 days) & & 102 & 48.8 \\
\hline Alcohol use (past 30 days) & & 55 & 26.3 \\
\hline Perceived Fair/Poor Health & & 87 & 41.6 \\
\hline Family History of Cancer & & 115 & 55.0 \\
\hline Returned the FIT kit & & 149 & 74.5 \\
\hline Prior CRC Screening & & 109 & 52.2 \\
\hline
\end{tabular}

NOTE: the two dependent variables are in bold font 
More than half (55\%) had family history of any cancer, and 52.2\% had a colonoscopy or sigmoidoscopy at least 12 -months before the FIT screening.

Figure 6 shows the distribution of the 209 participants across Jefferson County, Kentucky. In addition, Figure 7 shows the distribution of the 209 study participants along with the location of health clinics and hospitals and the 1- and 2-mile dissolved buffers, to illustrate that the nearest healthcare facility is within one to two miles from the participants' home residences.

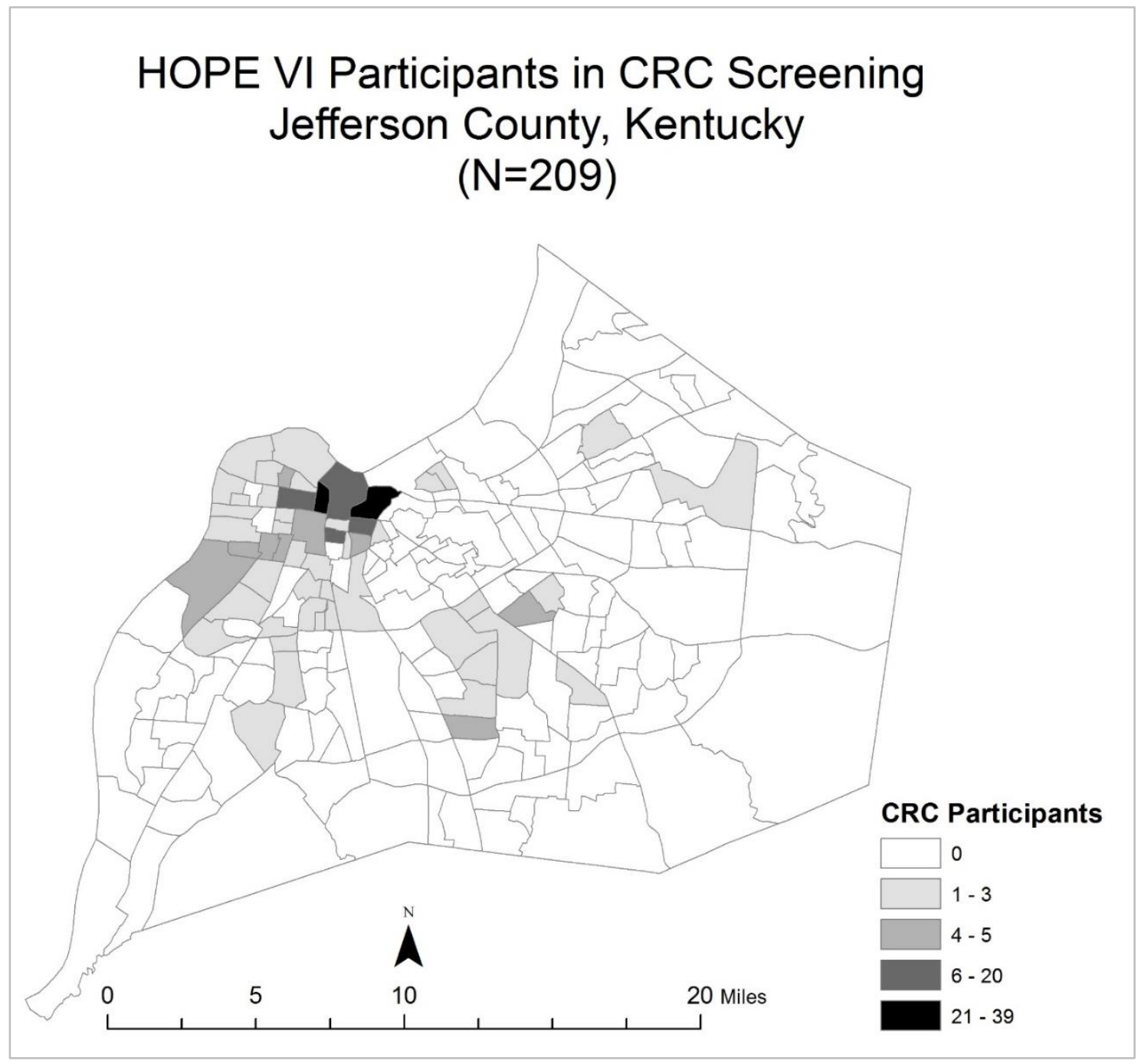

Figure 6. Distribution of the HOPE VI Participants in the CRC FIT Screening (N=209) 


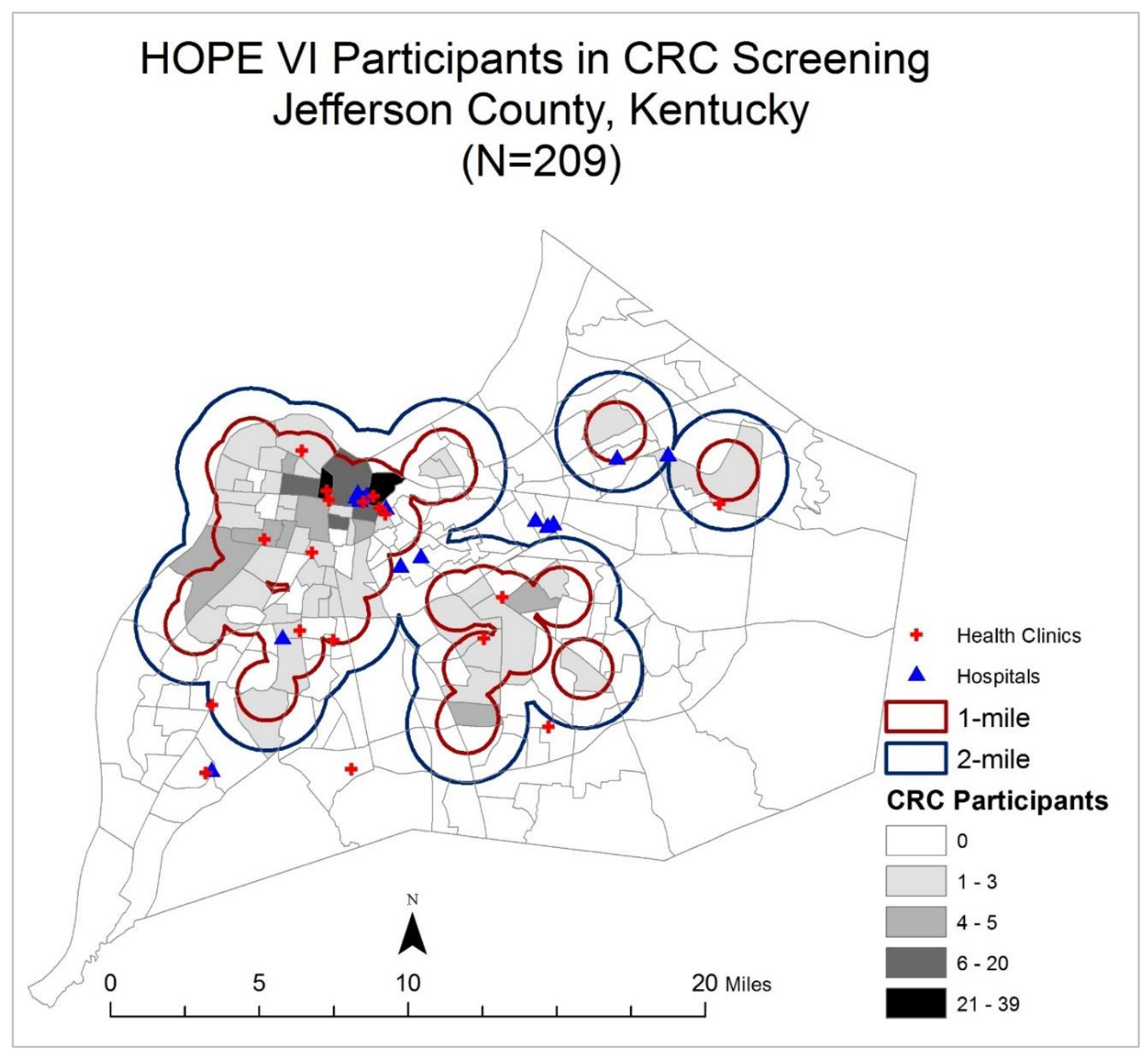

Figure 7. HOPE VI Participants' Proximity to Healthcare Facilities (N=209)

The 209 participants resided in 55 different census tracts (CT); 22 CTs had a single participant, 15 CTs had two participants, 3 CTs had three participants, 6 CTs had four participants, 3 CTs had five participants, 2 CTs had seven participants, and the last 4 CTs had 11, 19, 25 and respectively 39 participants. Thus, on one hand, 52 participants (25\%) were spread out across $37 \mathrm{CTs}$, and on another hand, 94 (45\%) participants resided within only four census tracts (out of 191). 


\section{$\underline{\text { Bivariate Analyses }}$}

\section{Individual-Level Factors by CRC Screening Behavior}

To answer the first and second research questions, focused on the individual characteristics that make a difference in individual FIT uptake and in prior CRC screening, all individual-level variables mentioned in the study's conceptual model were tested for association with each of the two dependent variables (1) return FIT status and (2) prior CRC screening, both measured as Yes/No.

\section{(1) Dependent Variable: FIT Return Status}

Table 3 shows that the group of people who returned the kit and the group of people who did not return the kit were not significantly different by gender, age, education, or marital status, but they were slightly different in terms of annual income, employment and insurance type. Specifically, the proportion of respondents with less than $\$ 10,000$ annual income was greater in the group that returned the kit $(84.8 \%)$ than in the group that did not return it $(78.1 \%)$.

The proportion of people employed in the group that returned the kit was smaller $(30.3 \%)$ than in the group that did not return the kit (43.8\%). Finally, among the group who returned the kit the proportion of participants with public health insurance (Passport/Medicaid, Medicare) is larger than in the group that did not return the kit. The group that returned the kit had $61.4 \%$ Medicaid and 18.6\% Medicare recipients as compared to $51.6 \%$ and respectively $14.1 \%$ in the other group. 


\section{Table 3}

$\underline{\text { Sociodemographic Characteristics by FIT Return Status (N=209) }}$

\begin{tabular}{|c|c|c|c|c|c|c|c|}
\hline \multirow[t]{2}{*}{ Variable } & \multirow[t]{2}{*}{ Category } & \multicolumn{2}{|c|}{$\begin{array}{c}\text { Not } \\
\text { Returned } \\
\end{array}$} & \multicolumn{2}{|c|}{ Returned } & \multicolumn{2}{|c|}{ Total } \\
\hline & & $\mathrm{N}$ & $\%$ & $\mathrm{~N}$ & $\%$ & $\mathrm{~N}$ & $\%$ \\
\hline \multirow{2}{*}{ Gender } & Male & 9 & 15.0 & 21 & 14.1 & 30 & 14.4 \\
\hline & Female & 51 & 85.0 & 128 & 85.9 & 179 & 85.6 \\
\hline \multirow{6}{*}{ Age Category } & Lowest - 49 & 15 & 25.0 & 34 & 22.8 & 49 & 23.4 \\
\hline & $50-54$ & 15 & 25.0 & 32 & 21.5 & 47 & 22.5 \\
\hline & $55-59$ & 13 & 21.7 & 34 & 22.8 & 47 & 22.5 \\
\hline & $60-64$ & 11 & 18.3 & 30 & 20.1 & 41 & 19.6 \\
\hline & $65-69$ & 3 & 5.0 & 11 & 7.4 & 14 & 6.7 \\
\hline & 70 - Highest & 3 & 5.0 & 8 & 5.4 & 11 & 5.3 \\
\hline \multirow{4}{*}{$\begin{array}{l}\text { Highest Year of } \\
\text { School } \\
\text { Completed }\end{array}$} & Elementary/Some HS & 22 & 36.7 & 48 & 32.7 & 70 & 33.8 \\
\hline & High school /GED & 26 & 43.3 & 71 & 48.3 & 97 & 46.9 \\
\hline & Some college/ technical school & 10 & 16.7 & 25 & 17.0 & 35 & 16.9 \\
\hline & College graduate & 2 & 3.3 & 3 & 2.0 & 5 & 2.4 \\
\hline \multirow{4}{*}{$\begin{array}{l}\text { Current Marital } \\
\text { Status }\end{array}$} & Married & 9 & 15.3 & 19 & 12.8 & 28 & 13.5 \\
\hline & Divorced/Separated & 5 & 8.5 & 20 & 13.4 & 25 & 12.0 \\
\hline & Widowed & 2 & 3.4 & 12 & 8.1 & 14 & 6.7 \\
\hline & Single & 43 & 72.9 & 98 & 65.8 & 141 & 67.8 \\
\hline \multirow{3}{*}{$\begin{array}{l}\text { Annual } \\
\text { Household } \\
\text { Income }\end{array}$} & $<\$ 10,000$ & 47 & 78.3 & 126 & 84.6 & 173 & 82.8 \\
\hline & $\$ 10,000$ to $<\$ 20,000$ & 9 & 15.0 & 11 & 7.4 & 20 & 9.6 \\
\hline & $\$ 20,000$ to $<\$ 75,000$ & 4 & 6.7 & 12 & 8.1 & 16 & 7.7 \\
\hline \multirow{4}{*}{$\begin{array}{l}\text { Employment } \\
\text { (Multiple } \\
\text { Choice) }\end{array}$} & Employed & 27 & 42.2 & 45 & 30.2 & 72 & 34.0 \\
\hline & Unable to work & 23 & 38.3 & 67 & 45.0 & 90 & 43.1 \\
\hline & Unemployed & 3 & 5.0 & 16 & 10.7 & 19 & 9.1 \\
\hline & Retired & 10 & 16.7 & 17 & 11.4 & 27 & 12.9 \\
\hline \multirow{6}{*}{$\begin{array}{l}\text { Insurance } \\
\text { (Multiple } \\
\text { Choice) }\end{array}$} & Passport/Medicaid & 33 & 55.0 & 89 & 59.7 & 122 & 58.4 \\
\hline & Medicare & 9 & 15.0 & 27 & 18.1 & 36 & 17.2 \\
\hline & ACA/self-purchase & 14 & 23.3 & 26 & 17.4 & 40 & 19.1 \\
\hline & Employer/spouse & 11 & 18.3 & 17 & 11.4 & 28 & 13.4 \\
\hline & Other & 8 & 13.3 & 29 & 19.5 & 37 & 17.7 \\
\hline & None & 2 & 3.1 & 5 & 3.4 & 7 & 3.3 \\
\hline \multicolumn{2}{|c|}{ Has Health Insurance } & 58 & 96.7 & 144 & 96.6 & 202 & 96.7 \\
\hline
\end{tabular}


The majority in the group with "other" insurance $(n=37)$ had WellCare $(23$, 62.2\%), while the remaining 14 people had Anthem, CIGNA, CareSource, Etna, InterState, MD2U, United Health, or Veteran Affairs; the proportion of participants with "other insurance" was $20 \%$ in the group that returned the kit, and $12.5 \%$ in the group that did not.

Table 4 shows that there were no significant differences in the average age or in the average fatalism scores between the group of participants who returned the kit and those who did not. In conclusion, gender, age, marital status, education, income, BMI (perceived or calculated), health behaviors (smokers, alcohol users) and fatalism measure were not associated with the participants' choice to return the kit or not.

\section{Table 4}

FIT Kit Return by Sociodemographic Numeric Characteristics ( $\mathrm{N}=209)$

\begin{tabular}{llrrrrr}
\hline Variable & Outcome & N & Mean & SD & t & p-value \\
\hline Age & No FIT & 60 & 55.53 & 7.2 & 0.406 & 0.685 \\
& FIT returned & 149 & 56 & 7.65 & & \\
\hline Fatalism & No FIT & 60 & 9.37 & 3.87 & 0.899 & 0.37 \\
& FIT returned & 149 & 9.85 & 3.39 & & \\
\hline
\end{tabular}

Table 5 displays the number and the proportion of participants who returned the kits across the individual key sociodemographic variables. It also shows the results of the chi-square tests of independence between returning the FIT kit and having or not a specific characteristic. 


\section{Table 5}

$\underline{\text { FIT Kit Return by Sociodemographic Discrete Characteristics }(\mathrm{N}=209)}$

\begin{tabular}{|c|c|c|c|c|c|}
\hline Variable & Category & $\begin{array}{l}\text { Kit Return } \\
(\mathrm{N})\end{array}$ & $\begin{array}{l}\text { Kit Return } \\
\quad(\%)\end{array}$ & $\begin{array}{l}\text { Chi- } \\
\text { Square }\end{array}$ & $\begin{array}{c}\mathrm{p}- \\
\text { value }\end{array}$ \\
\hline \multirow[t]{2}{*}{ Sex } & Male & 21 & 70.0 & 0.029 & .866 \\
\hline & Female & 128 & 71.5 & & \\
\hline \multirow[t]{2}{*}{ Married } & No & 130 & 71.8 & 0.186 & .666 \\
\hline & Yes & 19 & 67.9 & & \\
\hline \multirow[t]{2}{*}{ Single } & No & 51 & 75.0 & 0.677 & .411 \\
\hline & Yes & 98 & 69.5 & & \\
\hline \multirow[t]{2}{*}{ LTH Less than HS } & No & 101 & 72.7 & 0.381 & .537 \\
\hline & Yes & 48 & 68.6 & & \\
\hline \multirow[t]{2}{*}{ Employed } & No & 104 & 75.4 & 3.289 & .070 \\
\hline & Yes & 45 & 63.4 & & \\
\hline \multirow[t]{2}{*}{ Less than $\$ 10,000$} & No & 23 & 63.9 & 1.165 & .281 \\
\hline & Yes & 126 & 72.8 & & \\
\hline \multirow{2}{*}{$\begin{array}{l}\text { Public Housing } \\
\text { Development }\end{array}$} & No & 39 & 61.9 & 3.883 & .049 \\
\hline & Yes & 110 & 75.3 & & \\
\hline \multirow{2}{*}{$\begin{array}{l}\text { BMI high } \\
\text { (perceived) }\end{array}$} & Normal or underweight & 74 & 66.1 & 2.440 & .118 \\
\hline & Overweight or obese & 70 & 76.1 & & \\
\hline \multirow{2}{*}{$\begin{array}{l}\text { BMI high } \\
\text { (calculated) }\end{array}$} & Normal or underweight & 27 & 65.9 & 0.737 & .391 \\
\hline & Overweight or obese & 122 & 72.6 & & \\
\hline \multirow[t]{2}{*}{ Exercise } & No & 54 & 68.4 & 0.535 & .464 \\
\hline & Yes & 95 & 73.1 & & \\
\hline \multirow[t]{2}{*}{ Smoker } & No & 80 & 74.8 & 1.293 & .255 \\
\hline & Yes & 69 & 67.6 & & \\
\hline \multirow{2}{*}{$\begin{array}{l}\text { Alcohol use } \\
\text { (past } 30 \text { days) }\end{array}$} & No & 109 & 70.8 & 0.075 & .784 \\
\hline & Yes & 40 & 72.7 & & \\
\hline \multirow{2}{*}{$\begin{array}{l}\text { Perception of } \\
\text { Fair/Poor Health }\end{array}$} & No & 80 & 65.6 & 4.682 & .030 \\
\hline & Yes & 69 & 79.3 & & \\
\hline \multirow{2}{*}{$\begin{array}{l}\text { Family History of } \\
\text { Cancer }\end{array}$} & No & 72 & 76.6 & 2.348 & .125 \\
\hline & Yes & 77 & 67.0 & & \\
\hline \multirow{2}{*}{$\begin{array}{l}\text { Insured } \\
\text { (low variation) }\end{array}$} & No & 5 & 71.4 & 0.000 & .994 \\
\hline & Yes & 144 & 71.3 & & \\
\hline \multirow{2}{*}{$\begin{array}{l}\text { Provider } \\
\text { (low variation) }\end{array}$} & No & 4 & 40.0 & 5.025 & .025 \\
\hline & Yes & 145 & 72.9 & & \\
\hline
\end{tabular}

NOTE: significant p-values are in bold font 
Several variables were associated with returning the kit or not: participants who were residing in a large public housing development (75.3\%) appear to be more likely to return the kit than those who resided in mixed-income communities (61.9\%), such as scattered housing or market rentals. Participants who perceived their health as fair or poor (79.3\%) were significantly more likely to return the kit than those who perceived their health as good, very good or excellent (65.6\%); and, individuals who were not employed (75.4\%) were significantly more likely to return their kit than those who were employed (63.4\%), and a .10 critical level (marginally significant).

Finally, $72.9 \%$ of the participants who had a regular healthcare provider returned the kit as compared to $40 \%$ of their counterparts, but the lack of variation in this data item prevents its inclusion in further bivariate or multivariate analyses. A possible explanation for the lack of variation are the change in the current health insurance landscape, prompted by the Affordable Care Act.

Figure 8 and 9 show the distribution of participants who returned the FIT kit and respectively the distribution of participants with reactive result. It appears that the proportion of reactive results is greater in the census tracts with greater FIT return, as expected. There is no unusual pattern in these maps that would indicate a relationship between the FIT kits return and the participants' place of residence. Areas with higher number of participants have higher number of kits returned, and respectively higher number of participants with reactive results.

The 149 participants who returned the FIT kits resided in 48 of the 191 CTs of Jefferson County (Figure 8). There were 24 CTs with a single participant, 9 CTs with two participants, 5 CTs with three participants, 4 CTs had four participants, 3 CTs had five 
participants, and the last the three CTs with returned FITs included 12, 21 and respectively 27 participants. In other words, 60 of the 149 participants (40.2\%) with returned FIT kit resided within just 3 CTs, while 57 participants resided with 36 CTs.

The 42 participants with reactive FIT resided across 22 CTs (Figure 9); 16 CTs had a single participant with reactive FIT, 3 CTs had two participants, and the last 3 CTs had 3, 7 and respectively 10 residents. This means that about half of all of the residents with a reactive FIT were spread out across $19 \mathrm{CTs}$, while the other half were all located within 3 CTs.

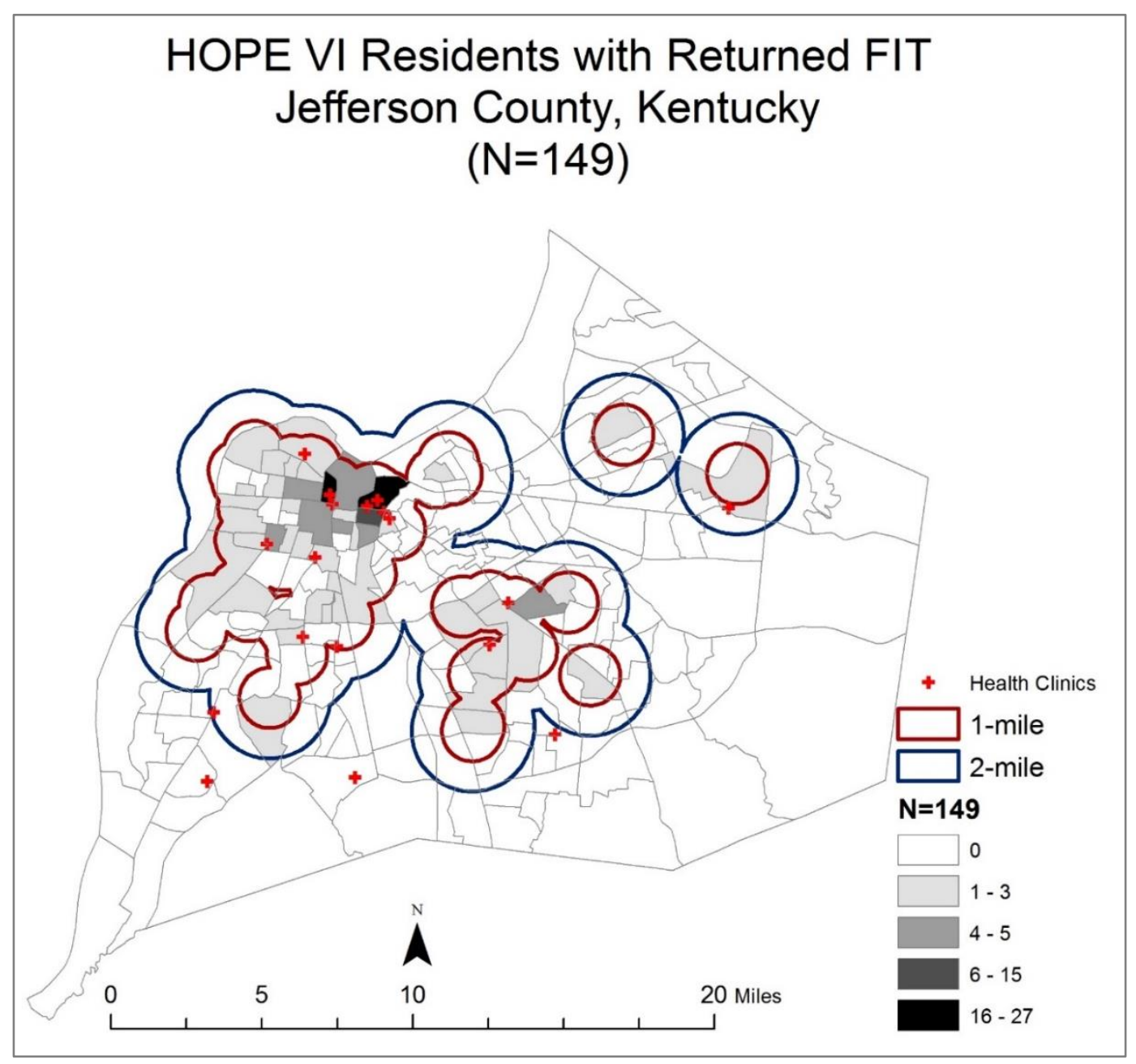

Figure 8. FIT Kit Returns ( $\mathrm{N}=149)$ 


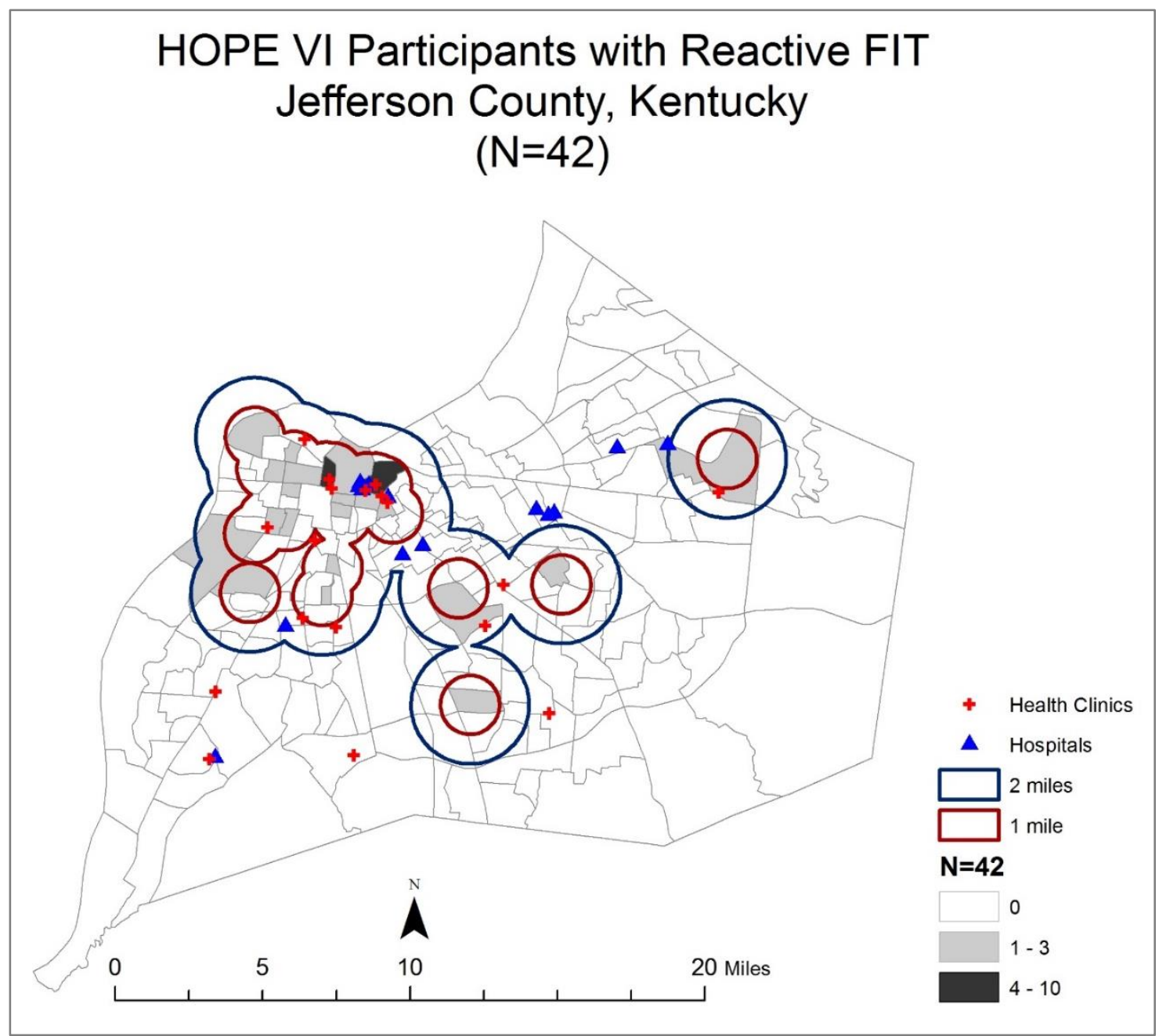

Figure 9. Participants with Reactive FIT $(\mathrm{N}=42)$

Thus, the answer to the first research question: "What are the individual characteristics that make a difference in individual FIT uptake?" is: The HOPE VI African-American residents who returned the FIT kit were more likely to perceive their health to be fair/poor, to not be employed, and to reside in larger public housing developments. 


\section{(2) Dependent Variable: Prior Colorectal Cancer Screening}

To answer the second research question regarding the individual characteristics that make a difference in a person's CRC screening behavior, all analyses presented above for the FIT uptake were replicated for the prior CRC screening (Yes/No) as a dependent variable.

Figure 10 shows the distribution of the $\mathrm{N}=109$ participants who had a prior CRC screening. Table 6 shows that the group of people who had prior colorectal cancer screening and the group of people who did not have prior CRC screening were slightly different across gender, age, marital status, employment, income and insurance types; they were not different in terms of education. Specifically, the group with prior CRC screening had a slightly larger proportion of males (16.5\% vs. $12 \%)$, they were more likely to be older, not single, and unable to work or retired.

The proportion of respondents with less than $\$ 10,000$ annual income was greater in the group with prior CRC screening (85.3\%) than in the group without prior screening (80\%). In the group with prior CRC screening $27 \%$ were employed; in the group without prior screening $44 \%$ were employed. Further, in the group with prior CRC screening 83.5\% had public health insurance (Passport/ Medicaid, Medicare) compared to 67\% in the group without prior CRC screening. The group with prior CRC had 61.5\% Medicaid and 22\% Medicare recipients as compared to 55\% and respectively $12 \%$ in the other group. 
Table 6

Prior CRC Screening by Sociodemographic Characteristics (N=209)

\begin{tabular}{|c|c|c|c|c|c|c|c|}
\hline \multirow[t]{2}{*}{ Variable } & \multirow[t]{2}{*}{ Category } & \multicolumn{2}{|c|}{$\begin{array}{l}\text { No Prior CRC } \\
\text { Screening }\end{array}$} & \multicolumn{2}{|c|}{$\begin{array}{l}\text { With Prior } \\
\text { CRC } \\
\text { Screening } \\
\end{array}$} & \multicolumn{2}{|c|}{ Total } \\
\hline & & $\mathrm{N}$ & $\%$ & $\mathrm{~N}$ & $\%$ & $\mathrm{~N}$ & $\%$ \\
\hline \multirow{2}{*}{ Gender } & Male & 12 & 12.0 & 18 & 16.5 & 30 & 14.4 \\
\hline & Female & 88 & 88.0 & 91 & 83.5 & 179 & 85.6 \\
\hline \multirow{6}{*}{$\begin{array}{l}\text { Age } \\
\text { Category }\end{array}$} & Lowest - 49 & 38 & 38.0 & 11 & 10.1 & 49 & 23.4 \\
\hline & $50-54$ & 20 & 20.0 & 27 & 24.8 & 47 & 22.5 \\
\hline & $55-59$ & 18 & 18.0 & 29 & 26.6 & 47 & 22.5 \\
\hline & $60-64$ & 16 & 16.0 & 25 & 22.9 & 41 & 19.6 \\
\hline & $65-69$ & 5 & 5.0 & 9 & 8.3 & 14 & 6.7 \\
\hline & 70 - Highest & 3 & 3.0 & 8 & 7.3 & 11 & 5.3 \\
\hline \multirow{4}{*}{$\begin{array}{l}\text { Highest } \\
\text { Year of } \\
\text { School } \\
\text { Completed }\end{array}$} & Elementary/ Some HS & 33 & 33.0 & 37 & 34.6 & 70 & 33.8 \\
\hline & High school /GED & 46 & 46.0 & 51 & 47.7 & 97 & 46.9 \\
\hline & Some college/ tech. school & 18 & 18.0 & 17 & 15.9 & 35 & 16.9 \\
\hline & College graduate & 3 & 3.0 & 2 & 1.9 & 5 & 2.4 \\
\hline \multirow{4}{*}{$\begin{array}{l}\text { Marital } \\
\text { Status }\end{array}$} & Married & 10 & 10.1 & 18 & 16.5 & 28 & 13.5 \\
\hline & Divorced/Separated & 10 & 10.1 & 15 & 13.8 & 25 & 12.0 \\
\hline & Widowed & 7 & 7.1 & 7 & 6.4 & 14 & 6.7 \\
\hline & Single & 72 & 72.7 & 69 & 63.3 & 141 & 67.8 \\
\hline \multirow{3}{*}{$\begin{array}{l}\text { Annual } \\
\text { Household } \\
\text { Income }\end{array}$} & $<\$ 10,000$ & 80 & 80.0 & 93 & 85.3 & 173 & 82.8 \\
\hline & $\$ 10,000$ to $<\$ 20,000$ & 14 & 14.0 & 6 & 5.5 & 20 & 9.6 \\
\hline & $\$ 20,000$ to $<\$ 75,000$ & 6 & 6.0 & 10 & 9.2 & 16 & 7.7 \\
\hline \multirow{4}{*}{$\begin{array}{l}\text { Employment } \\
\text { (Multiple } \\
\text { Choice) }\end{array}$} & Employed (Y/N) & 44 & 44.0 & 28 & 25.7 & 72 & 34.4 \\
\hline & Unable to work $(\mathrm{Y} / \mathrm{N})$ & 32 & 32.0 & 58 & 53.2 & 90 & 43.1 \\
\hline & Unemployed (Y/N) & 16 & 16.0 & 12 & 11.0 & 28 & 13.4 \\
\hline & Retired $(\mathrm{Y} / \mathrm{N})$ & 10 & 10.0 & 17 & 15.6 & 27 & 12.9 \\
\hline \multirow{6}{*}{$\begin{array}{l}\text { Insurance } \\
\text { (Multiple } \\
\text { Choice) }\end{array}$} & Passport/Medicaid & 55 & 55.0 & 67 & 61.5 & 122 & 58.4 \\
\hline & Medicare & 12 & 12.0 & 24 & 22.0 & 36 & 17.2 \\
\hline & ACA/self-purchase & 21 & 21.0 & 19 & 17.4 & 40 & 19.1 \\
\hline & Employer/spouse & 15 & 15.0 & 13 & 11.9 & 28 & 13.4 \\
\hline & Other & 16 & 16.0 & 21 & 19.3 & 37 & 17.7 \\
\hline & None & 6 & 6.0 & 1 & 0.9 & 7 & 3.3 \\
\hline \multicolumn{2}{|c|}{ Has Health Insurance } & 94 & 94.0 & 108 & 99.1 & 202 & 96.7 \\
\hline
\end{tabular}


The 109 participants with a prior CRC screening (Figure 10) were distributed across 39 CTs: 19 CTs with one participant, 11 CTs with two participants, 5 CTs with three participants, while the last 4 CTs had 7, 8, 15, and respectively 20 participants.

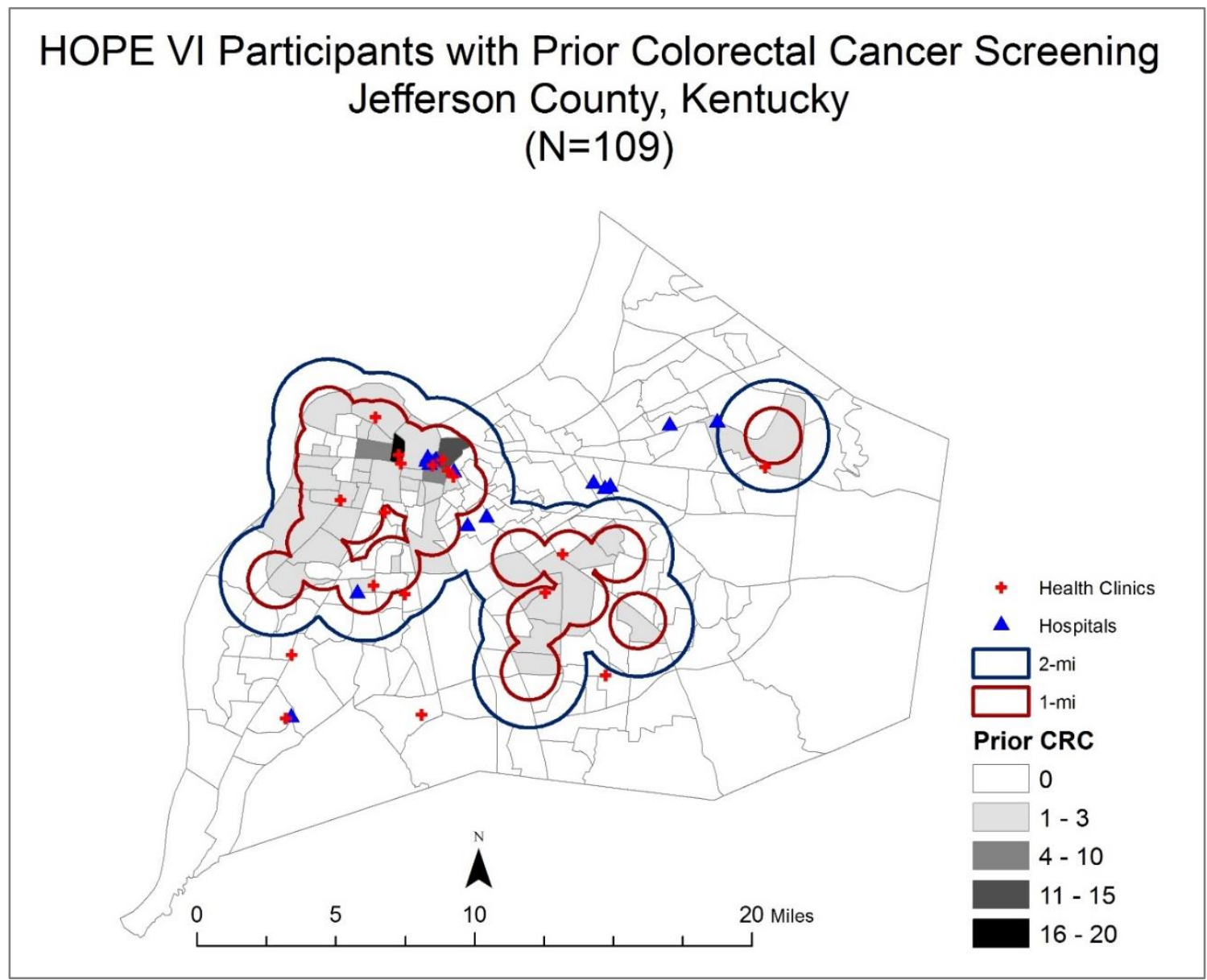

Figure 10. Prior Colorectal Cancer Screening

To test the potentially significant differences identified in Table 6, Chi-Square tests of independence (Table 7) and t-tests comparisons of means (Table 8) were conducted. 
Table 7

Prior CRC Screening by Sociodemographic Discrete Characteristics ( $N=209)$

\begin{tabular}{|c|c|c|c|c|c|}
\hline & & $\begin{array}{c}\text { Prior } \\
\text { CRC }(\mathrm{N})\end{array}$ & $\begin{array}{c}\text { Prior } \\
\text { CRC }(\%)\end{array}$ & $\begin{array}{r}\text { Chi- } \\
\text { Square }\end{array}$ & $\mathrm{p}$ \\
\hline \multirow[t]{2}{*}{ Age 50 to 75} & No & 11 & 22.4 & 22.632 & .000 \\
\hline & Yes & 98 & 61.3 & & \\
\hline \multirow[t]{2}{*}{ Sex } & Male & 18 & 60.0 & .864 & .353 \\
\hline & Female & 91 & 50.8 & & \\
\hline \multirow[t]{2}{*}{ Married } & No & 91 & 50.3 & 1.907 & .167 \\
\hline & Yes & 18 & 64.3 & & \\
\hline \multirow[t]{2}{*}{ Single } & No & 40 & 58.8 & 1.797 & .180 \\
\hline & Yes & 69 & 48.9 & & \\
\hline \multirow[t]{2}{*}{ LTH Less than HS } & No & 72 & 51.8 & .021 & .885 \\
\hline & Yes & 37 & 52.9 & & \\
\hline \multirow{2}{*}{ Employed } & No & 82 & 59.4 & 8.597 & .003 \\
\hline & Yes & 27 & 38.0 & & \\
\hline \multirow[t]{2}{*}{ Less than $\$ 10,000$} & No & 16 & 44.4 & 1.036 & .309 \\
\hline & Yes & 93 & 53.8 & & \\
\hline \multirow{2}{*}{$\begin{array}{l}\text { Public Housing } \\
\text { Development }\end{array}$} & No & 31 & 49.2 & .314 & .575 \\
\hline & Yes & 78 & 53.4 & & \\
\hline \multirow{2}{*}{$\begin{array}{l}\text { BMI high } \\
\text { (perceived) }\end{array}$} & Normal or underweight & 55 & 49.1 & 1.113 & .291 \\
\hline & Overweight or obese & 52 & 56.5 & & \\
\hline \multirow{2}{*}{$\begin{array}{l}\text { BMI high } \\
\text { (calculated) }\end{array}$} & Normal or underweight & 21 & 51.2 & .018 & .894 \\
\hline & Overweight or obese & 88 & 52.4 & & \\
\hline \multirow[t]{2}{*}{ Exercise } & No & 46 & 58.2 & 1.878 & .171 \\
\hline & Yes & 63 & 48.5 & & \\
\hline \multirow[t]{2}{*}{ Smoker } & No & 59 & 55.1 & .784 & .376 \\
\hline & Yes & 50 & 49.0 & & \\
\hline \multirow{2}{*}{$\begin{array}{l}\text { Alcohol use } \\
\text { (past } 30 \text { days) }\end{array}$} & No & 86 & 55.8 & 3.195 & .074 \\
\hline & Yes & 23 & 41.8 & & \\
\hline \multirow[t]{2}{*}{ Fair/Poor Health } & No & 55 & 45.1 & 5.873 & .015 \\
\hline & Yes & 54 & 62.1 & & \\
\hline \multirow{2}{*}{$\begin{array}{l}\text { Family History of } \\
\text { Cancer }\end{array}$} & No & 43 & 45.7 & 2.812 & .094 \\
\hline & Yes & 66 & 57.4 & & \\
\hline \multirow{2}{*}{$\begin{array}{l}\text { Health Insurance } \\
\text { (low variation) }\end{array}$} & No & 1 & & 4.162 & .041 \\
\hline & Yes & 108 & & & \\
\hline \multirow{2}{*}{$\begin{array}{l}\text { Regular Provider } \\
\text { (low variation) }\end{array}$} & No & 2 & & 4.351 & .037 \\
\hline & Yes & 107 & & & \\
\hline
\end{tabular}

NOTE: significant p-values are in bold font 
There was a significant association between residents' age and the prior CRC screening; residents older than 50 were more likely to have had a sigmoidoscopy or a colonoscopy in the past (more than 12-months prior). Residents who were employed ( $\mathrm{p}=.003)$ or perceived their health to be good/very good/excellent $(\mathrm{p}=.015)$ were less likely to have had a prior CRC screening. The alcohol use and family history of cancer were only statistically associated with prior CRC screening at $\mathrm{p}<.10$. All other variables - gender, marital status, education, income, BMI (perceived or calculated) and health behaviors (smokers, alcohol users) -- were not associated with prior CRC screening. The extremely small proportion of participants without health insurance and without a regular healthcare provider, indicates that participants in this study, in spite of their low-income status, did not experience lack of access to healthcare.

Table 8 shows that the two groups were significantly different in age $(\mathrm{p}<.01)$, and that they were not different in their health beliefs (fatalism) $(\mathrm{p}=.269)$. Employment status $(\mathrm{p}=.003)$, and perception of a fair/poor health $(\mathrm{p}=.015)$ are associated with prior CRC screening.

\section{Table 8}

Prior CRC Screening by Sociodemographic Numeric Characteristics $(\mathrm{N}=209)$

\begin{tabular}{llrrrrr}
\hline & & N & Mean & SD & t & p-value \\
\hline Age & No Prior Screening & 100 & 53.84 & 7.475 & -3.861 & $\mathbf{. 0 0 0}$ \\
& Prior Screening & 109 & 57.72 & 7.068 & & \\
\hline Fatalism & No Prior Screening & 100 & 9.43 & 3.50 & -1.109 & .269 \\
& Prior Screening & 109 & 9.97 & 3.56 & & \\
\hline
\end{tabular}

NOTE: significant p-values are in bold font 
Thus, the answer to the second research question: "What are the individual characteristics that make a difference in a person's CRC screening behavior?" is: The HOPE VI African-American residents with prior CRC screening were more likely to be age 50 or older, to perceive their health as fair/poor, to have family history of cancer, to be unemployed, and to not use alcohol on a regular basis.

\section{Neighborhood Factors by CRC Screening Behavior}

To answer the third research question regarding the association between the neighborhood characteristics and the screening behavior, a series of independent t-tests were conducted to compare the means of census tract variables between the two groups defined by each of the two dependent variables: FIT returned vs. FIT not returned, and Prior CRC screening vs. No Prior CRC screening. The comparisons of means of census tract socioeconomic variables between those who returned the kit $(\mathrm{N}=149)$ and those who did not $(\mathrm{N}=60)$, and respectively between those who had a prior CRC screening $(\mathrm{N}=109)$ and those who did not $(\mathrm{N}=100)$ are shown in Table 9. The inspection of the means and standard deviations along with the non-significant p-values, showed that overall the neighborhood characteristics were very similar.

The participants in this study resided in neighborhoods that were primarily African American (63\%), with an average unemployment rate of over $20 \%$. About $30 \%$ of the residents in these neighborhoods have an annual household income below $\$ 10,000$, and about $18 \%$ have less than high school education. 


\section{Table 9}

Descriptive Statistics for Socioeconomic Indicators at Census Tract Level

\begin{tabular}{|c|c|c|c|c|c|c|c|c|}
\hline & \multicolumn{4}{|c|}{ Return FIT } & \multicolumn{4}{|c|}{ Prior CRC } \\
\hline & & Mean & SD & $\mathrm{P}$ & & Mean & SD & $\mathrm{P}$ \\
\hline \multirow[t]{2}{*}{ Household Income } & No & $\$ 21,379$ & $\$ 9,333$ & .666 & No & $\$ 21,812$ & $\$ 10,546$ & .922 \\
\hline & Yes & $\$ 22,093$ & $\$ 11,321$ & & Yes & $\$ 21,958$ & $\$ 11,020$ & \\
\hline \multirow[t]{2}{*}{ Family Income } & No & $\$ 27,648$ & $\$ 14,496$ & .721 & No & $\$ 28,133$ & $\$ 16,390$ & .880 \\
\hline & Yes & $\$ 28,595$ & $\$ 17,907$ & & Yes & $\$ 28,496$ & $\$ 17,551$ & \\
\hline \multirow{2}{*}{$\begin{array}{l}\text { Unemployment Rate } \\
(\%)\end{array}$} & No & $21.6 \%$ & $10.3 \%$ & .658 & No & $20.9 \%$ & $10.1 \%$ & .867 \\
\hline & Yes & $20.9 \%$ & $10.3 \%$ & & Yes & $21.2 \%$ & $10.4 \%$ & \\
\hline \multirow{2}{*}{$\begin{array}{l}\text { Using public } \\
\text { transportation }(\%)\end{array}$} & No & $15.7 \%$ & $10.4 \%$ & .693 & No & $15.4 \%$ & $10.3 \%$ & .855 \\
\hline & Yes & $15.0 \%$ & $10.6 \%$ & & Yes & $15.1 \%$ & $10.8 \%$ & \\
\hline \multirow{2}{*}{$\begin{array}{l}\text { Income below } \\
\$ 10,000(\%)\end{array}$} & No & $29.0 \%$ & $15.2 \%$ & .765 & No & $28.8 \%$ & $15.5 \%$ & .845 \\
\hline & Yes & $28.3 \%$ & $15.6 \%$ & & Yes & $28.3 \%$ & $15.4 \%$ & \\
\hline \multirow{2}{*}{$\begin{array}{l}\text { With Earnings } \\
(\%)\end{array}$} & No & $64.2 \%$ & $9.5 \%$ & .630 & No & $64.0 \%$ & $9.1 \%$ & .643 \\
\hline & Yes & $63.5 \%$ & $9.6 \%$ & & Yes & $63.4 \%$ & $9.9 \%$ & \\
\hline \multirow{2}{*}{$\begin{array}{l}\text { TANF } \\
(\%)\end{array}$} & No & $5.8 \%$ & $3.2 \%$ & .763 & No & $5.9 \%$ & $3.1 \%$ & .886 \\
\hline & Yes & $6.0 \%$ & $3.0 \%$ & & Yes & $5.9 \%$ & $3.0 \%$ & \\
\hline \multirow{2}{*}{$\begin{array}{l}\text { Food Stamps } \\
(\%)\end{array}$} & No & $45.7 \%$ & $21.1 \%$ & .712 & No & $45.1 \%$ & $21.3 \%$ & .872 \\
\hline & Yes & $44.5 \%$ & $21.7 \%$ & & Yes & $44.6 \%$ & $21.8 \%$ & \\
\hline \multirow{2}{*}{$\begin{array}{l}\text { Public Health } \\
\text { Insurance }(\%)\end{array}$} & No & $55.6 \%$ & $12.6 \%$ & .639 & No & $55.0 \%$ & $12.5 \%$ & .993 \\
\hline & Yes & $54.7 \%$ & $12.6 \%$ & & Yes & $54.9 \%$ & $12.8 \%$ & \\
\hline \multirow{2}{*}{$\begin{array}{l}\text { Uninsured } \\
(\%)\end{array}$} & No & $16.4 \%$ & $3.5 \%$ & .297 & No & $16.1 \%$ & $3.6 \%$ & .462 \\
\hline & Yes & $15.8 \%$ & $3.7 \%$ & & Yes & $15.8 \%$ & $3.7 \%$ & \\
\hline \multirow{2}{*}{$\begin{array}{l}\text { AA/ Black } \\
(\%)\end{array}$} & No & $66.5 \%$ & $27.8 \%$ & .283 & No & $62.8 \%$ & $27.3 \%$ & .755 \\
\hline & Yes & $62.1 \%$ & $26.4 \%$ & & Yes & $63.9 \%$ & $26.4 \%$ & \\
\hline \multirow{2}{*}{$\begin{array}{l}\text { Less Than High } \\
\text { School } \\
(\%)\end{array}$} & No & $18.2 \%$ & $8.6 \%$ & .781 & No & $17.9 \%$ & $7.7 \%$ & .923 \\
\hline & Yes & $17.8 \%$ & $7.6 \%$ & & Yes & $18.0 \%$ & $8.0 \%$ & \\
\hline \multirow[t]{2}{*}{ Proximity (miles) } & No & 0.70 & 0.57 & .164 & No & 0.82 & 0.78 & .703 \\
\hline & Yes & 0.84 & 0.80 & & Yes & 0.78 & 0.71 & \\
\hline
\end{tabular}

NOTE: significant p-values (if any) are in bold font 
Furthermore, the majority of the 209 residents were located within one mile from a healthcare facility (average $=0.8$ standard deviation $=0.75, \mathrm{~N}=209$ ); there was one resident who recently moved to Lexington, KY (74.5 miles away) who was excluded from the proximity analysis.

There were no significant differences in the socioeconomic characteristics between the neighborhoods of residents of the individuals who returned the kit and of those who did not. Similarly, there were no significant differences in the socioeconomic characteristics of the neighborhoods where the residents with prior CRC screening reside and the neighborhoods of those who did not have a CRC screening before this study. Given the lack of variation in socioeconomic characteristics at census tract level, it is difficult to tell whether residing in a mixed-income community would make a difference in health behaviors.

To summarize the bivariate analyses, none of the neighborhood level variables were associated with any of the two dependent variables. However, the following individual binary variables were significantly associated (at $\mathrm{p}<.05$, or marginally at $\mathrm{p}<.10)$ with the two dependent variables, FIT kit return or with the Prior Screening: perception of fair/poor health, employment status, residence in a large public housing development, family history of cancer, alcohol use during the past 30 days, and being age 50 or older.

Thus, the answer for the third research question "What are the neighborhood factors that make a difference in a person's CRC screening behavior?" is that results are inconclusive due to insufficient variation in neighborhood level variables; participants reside in neighborhoods that are extremely similar in their socioeconomic status. 
Finally, the answer for the fourth research question "Is there a relationship between proximity to healthcare facilities and the prior utilization of CRC screening services among urban African Americans, current or former HOPE VI public housing residents?", is that proximity to healthcare facilities does not seem to matter in prior CRC screening behavior; respondents' age (50 or older) and their perception of having a fair/poor health status are the best predictors for having had a colonoscopy in the past or not.

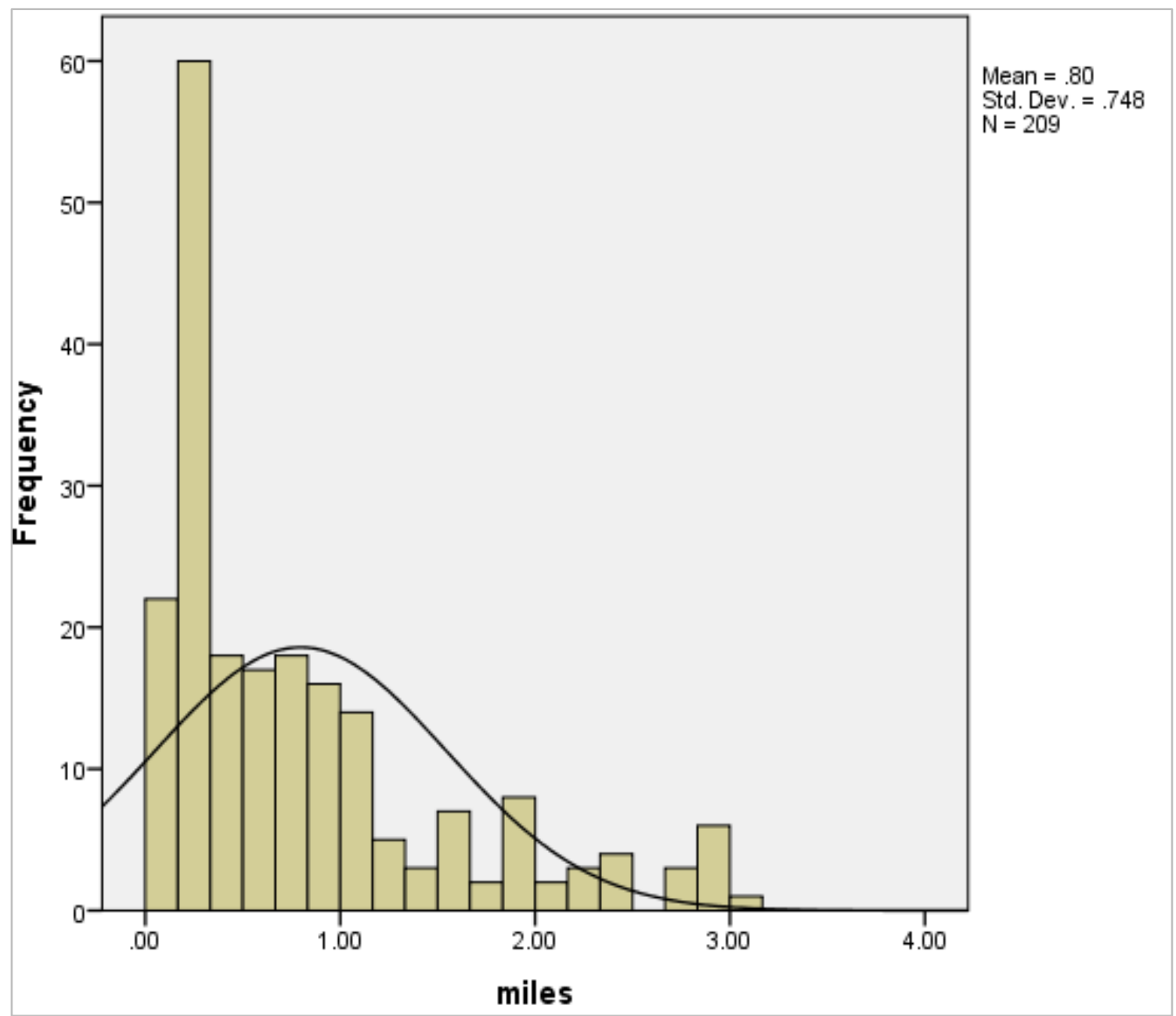

Figure 11. Histogram for Proximity to Healthcare Facilities (in miles) 


\section{$\underline{\text { Multivariate Analyses }}$}

The multivariate analyses followed closely the conceptual model developed using the Andersen framework, presented earlier in this document (Figure 2). From the original list of variables measured at individual level, only the participant's perceived health and the employment status were associated with the two dependent variables. Housing type (large development or scattered housing) was significantly associated with FIT kit uptake/return, and family history of cancer and alcohol use were associated with prior CRC screening. Using a backward conditional elimination, logistic regression models were conducted using all of these significant or marginally significant variables to predict the likelihood of FIT uptake and of CRC prior screening. None of the neighborhood level variables were significant, therefore none of these were included in the multivariate analyses.

Table 10 shows the first (full model) and last (best model) iteration of the logistic regression, using a backward elimination method, which predicted the likelihood that participants would return the FIT kit. Similarly Table 11, shows the first (full model) and last (best model) iteration of the logistic regression, using a backward elimination method, which predicted the likelihood that participants had a prior CRC screening. The full model for both of these analyses included all of the independent variables that were found significant during the bivariate analyses, meaning they were significantly associated with the FIT return or with the prior screening.

Table 10 shows the results of logistic regression for two models: (1) the full model, where all of the variables that were significantly associated with the FIT return or with the prior screening were included; (2) the best fitting logistic regression model that 
was found by using a backward conditional method. The full model shows that only health status was significantly associated with returning the FIT; people who perceived their health as fair or poor were almost twice as likely to return the kit. The best and simplest logistic regression model shows that indeed, people who perceived their health to be fair or poor were twice as likely $(\mathrm{OR}=2.055, \mathrm{p}<.05)$ to return the kit than those who perceived their health to be good, very good or excellent.

In addition, the residents of larger public housing developments $(\mathrm{OR}=1.873$, $\mathrm{p}<.10)$ were $87.3 \%$ more likely to return the FIT kit than those who reside in scattered housing or in rentals on the regular housing market. Employment made no difference in the likelihood of kit return after adjusting for respondent's perceived health status, and neither did alcohol use or family history of cancer. Table 11 shows that adjusting for age made no difference in predicting the likelihood of FIT return; the final / best model was the same.

\section{Table 10}

Logistic Regression Predicting FIT Uptake/Return (N=209)

\begin{tabular}{llrrrrrr}
\hline \multirow{2}{*}{$\begin{array}{l}\text { FIT } \\
\text { Return }\end{array}$} & \multicolumn{1}{c}{ Predictors (IV) } & & & & \multicolumn{2}{c}{ Odds } & \multicolumn{2}{c}{ OR 95\% C.I. } \\
\cline { 7 - 9 } & & \multicolumn{1}{c}{ B } & S.E. & Sig. & Ratio & Lower & Upper \\
\hline \multirow{4}{*}{ Full } & Employed & -.398 & .338 & .238 & .671 & .346 & 1.302 \\
Model & Public Housing Development & .531 & .335 & .113 & 1.700 & .881 & 3.280 \\
& Family History of Cancer & -.523 & .324 & .106 & .593 & .314 & 1.118 \\
& Fair/Poor Health & .677 & .345 &. $\mathbf{0 5 0}$ & 1.968 & 1.001 & 3.869 \\
& Constant & .673 & .401 & .093 & 1.961 & & \\
\hline \multirow{3}{*}{ Best } & Public Housing Development & .627 & .327 & $\mathbf{. 0 5 5}$ & 1.873 & .987 & 3.552 \\
Model & Fair/Poor Health & .696 & .329 & $\mathbf{. 0 3 4}$ & 2.005 & 1.053 & 3.821 \\
& Constant & .224 & .287 & .435 & 1.252 & & \\
\hline
\end{tabular}

NOTE: significant p-values are in bold font 


\section{Table 11}

$\underline{\text { Logistic Regression Predicting FIT Uptake/Return (N=209): Age-Adjusted Results }}$

\begin{tabular}{|c|c|c|c|c|c|c|c|}
\hline & \multirow{2}{*}{ Predictors (IV) } & \multirow{2}{*}{$\mathrm{B}$} & \multirow{2}{*}{ S.E. } & \multirow{2}{*}{ Sig. } & \multirow{2}{*}{$\begin{array}{l}\text { Odds } \\
\text { Ratio }\end{array}$} & \multicolumn{2}{|c|}{ OR $95 \%$ C.I. } \\
\hline & & & & & & Lower & Upper \\
\hline \multirow{7}{*}{$\begin{array}{l}\text { Full } \\
\text { Model }\end{array}$} & Employment & -.469 & .359 & .191 & .626 & .310 & 1.264 \\
\hline & Public Housing Development & .552 & .337 & .102 & 1.737 & .896 & 3.365 \\
\hline & Alcohol & .283 & .375 & .451 & 1.327 & .636 & 2.766 \\
\hline & Family History of Cancer & -.523 & .324 & .107 & .593 & .314 & 1.119 \\
\hline & Fair/Poor Health & .691 & .346 & .046 & 1.996 & 1.013 & 3.932 \\
\hline & Age 50 or older & -.233 & .400 & .560 & .792 & .362 & 1.734 \\
\hline & Constant & .854 & .508 & .093 & 2.350 & & \\
\hline \multirow{3}{*}{$\begin{array}{l}\text { Best } \\
\text { Model }\end{array}$} & Public Housing Dev. & .627 & .327 & .055 & 1.873 & .987 & 3.552 \\
\hline & Fair/Poor Health & .696 & .329 & .034 & 2.005 & 1.053 & 3.821 \\
\hline & Constant & .224 & .287 & .435 & 1.252 & & \\
\hline
\end{tabular}

NOTE: significant p-values are in bold font

Similarly, Table 12 presents the results of the logistic regression predicting the likelihood that study participants had a prior CRC screening at least 12 months prior to the study. The results show that individuals who are employed were significantly less likely to have had a CRC screening in the past (OR=.502, CI: .270-.934). This means that people without employment earnings have $1 / 0.502=1.992$ odds ratio or are two times more likely to have had a prior CRC screening than those who were employed. The significant association between employment status and the respondent's age of 50-75 (Chi-square $=24.49, \mathrm{p}<.001)$, provides further insight in this result: older individuals were more likely to have had a CRC screening, and they are more likely to be unemployed. The family history of cancer was only marginally significant $(\mathrm{p}=.095)$ when predicting prior CRC screening. 


\section{Table 12}

$\underline{\text { Logistic Regression Predicting Prior CRC Screening (N=209) }}$

\begin{tabular}{|c|c|c|c|c|c|c|c|}
\hline \multirow{2}{*}{$\begin{array}{l}\text { Prior } \\
\text { CRC }\end{array}$} & \multirow{2}{*}{ Predictors (IV) } & \multirow[b]{2}{*}{$\mathrm{B}$} & \multirow[b]{2}{*}{ S.E. } & \multirow[b]{2}{*}{ Sig. } & \multirow{2}{*}{$\begin{array}{l}\text { Odds } \\
\text { Ratio }\end{array}$} & \multicolumn{2}{|c|}{ OR $95 \%$ C.I. } \\
\hline & & & & & & Lower & Upper \\
\hline \multirow{6}{*}{$\begin{array}{l}\text { Full } \\
\text { Model }\end{array}$} & Employed & -.689 & .317 & .030 & .502 & .270 & .934 \\
\hline & Public Housing Development & .127 & .319 & 690 & 1.136 & .608 & 2.122 \\
\hline & Alcohol use (past 30 days) & -.432 & .335 & .198 & .649 & .337 & 1.253 \\
\hline & Family History of Cancer & .485 & .290 & .095 & 1.624 & 919 & 2.870 \\
\hline & Fair/Poor Health & .458 & .303 & .130 & 1.581 & .873 & 2.861 \\
\hline & Constant & -.109 & .374 & .771 & .897 & & \\
\hline \multirow{3}{*}{$\begin{array}{l}\text { Best } \\
\text { Model }\end{array}$} & Employed & -.741 & .309 & .016 & .476 & .260 & .873 \\
\hline & Fair/Poor Health & .522 & .297 & .079 & 1.685 & .941 & 3.017 \\
\hline & Constant & .123 & .226 & .586 & 1.131 & & \\
\hline
\end{tabular}

NOTE: significant p-values are in bold font

The simplest and best model that predicts the prior CRC screening (Table 12), shows that participants with employment were significantly less likely $(\mathrm{OR}=0.476$, $\mathrm{p}<.05)$, that is $1 / 0.476=2.1$ times less likely, to get a CRC screening than those without employment. The place of residence made no difference in the likelihood to have had CRC screening prior to this study; thus, respondents who reside in large public housing developments were just as likely to have had prior CRC screening as those residing in scattered housing or market rental apartments.

Table 13 shows that the age adjustment made a significant difference in predicting the likelihood of having a prior CRC screening or not; the final / best model continues to include health status, but the age of the respondent (being age 50 or older) is now in the model instead of employment status. Age and employment are highly associated with each other, and between the two, age was a stronger predictor of the prior CRC screening than employment status. 


\section{Table 13}

$\underline{\text { Logistic Regression Predicting Prior CRC Screening (N=209): Age-Adjusted Results }}$

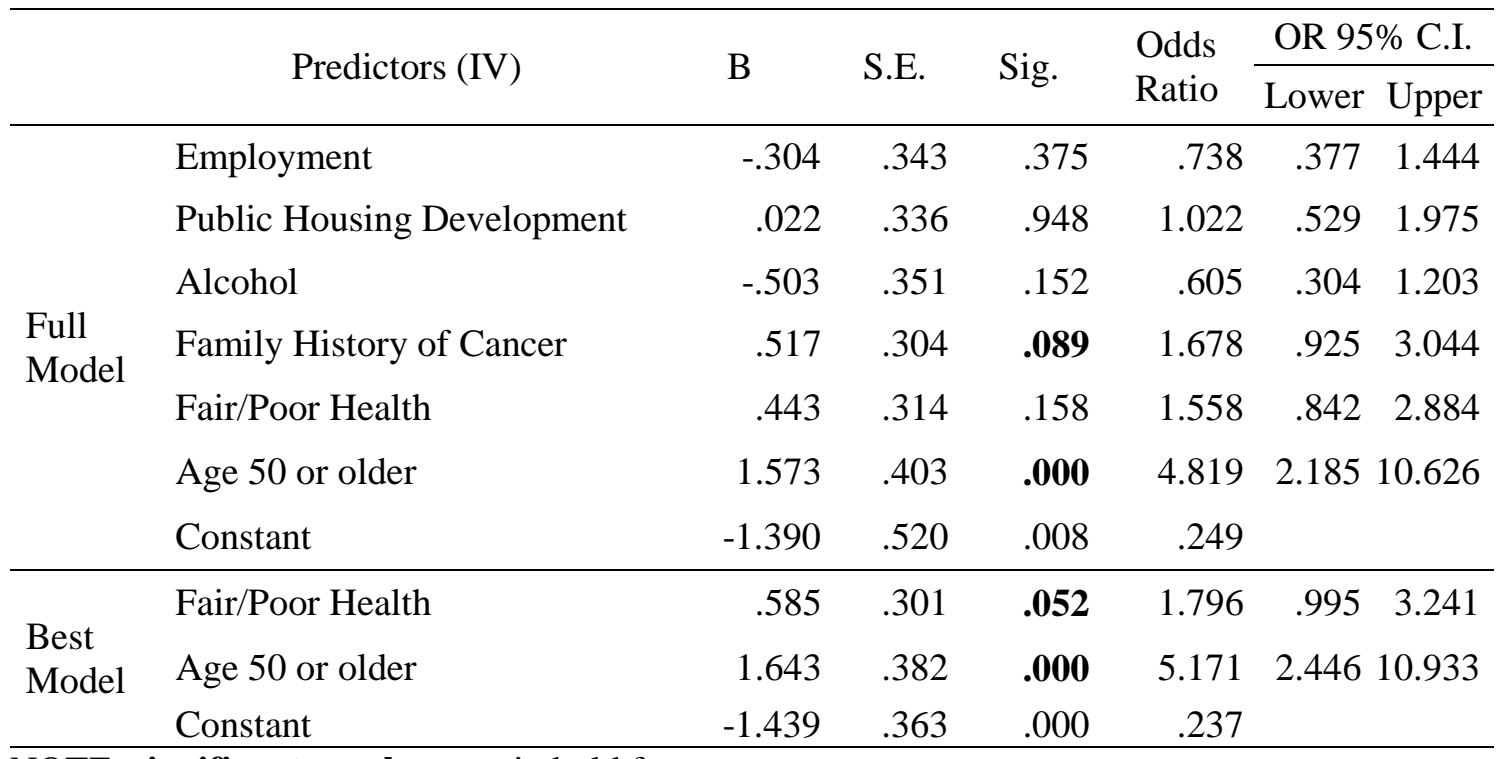

NOTE: significant p-values are in bold font

This finding is not surprising, given that physicians recommend colonoscopies to all individuals ages 50 or older. However, the significant difference in prior CRC screening between the employed and unemployed is more interesting to this study, because one would expect that people who are employed would be more responsive to using a take home FIT kit.

Adjusting for age did not make a difference in the prediction of FIT kit return (Table 11), but it did for the prior screening of CRC (Table 13); people older than 50 were five times more likely to have a colonoscopy or sigmoidoscopy as compared to people younger than 50 years. This is not a surprise considering that physicians recommend colonoscopies to all of their patients ages 50 or older. Also, older public housing residents are more likely to be retired or disabled, hence they are without employment earnings (87\% of participants without employment earnings were ages 50 to 75 years old) and to reside in larger public housing buildings, such as the "senior high- 
rises". Because age and employment are highly associated with each other, they are generally not included in the same regression model; rather, they are tested separately depending on whether the interest is in differences across age groups or across employment groups.

The common variable between the two best logistic regression models predicting screening behaviors, FIT uptake and respectively CRC prior screening, is the perception of fair/poor health. The distribution of the 87 residents who perceived their health as fair/poor is presented using a choropleth map (Figure 12).

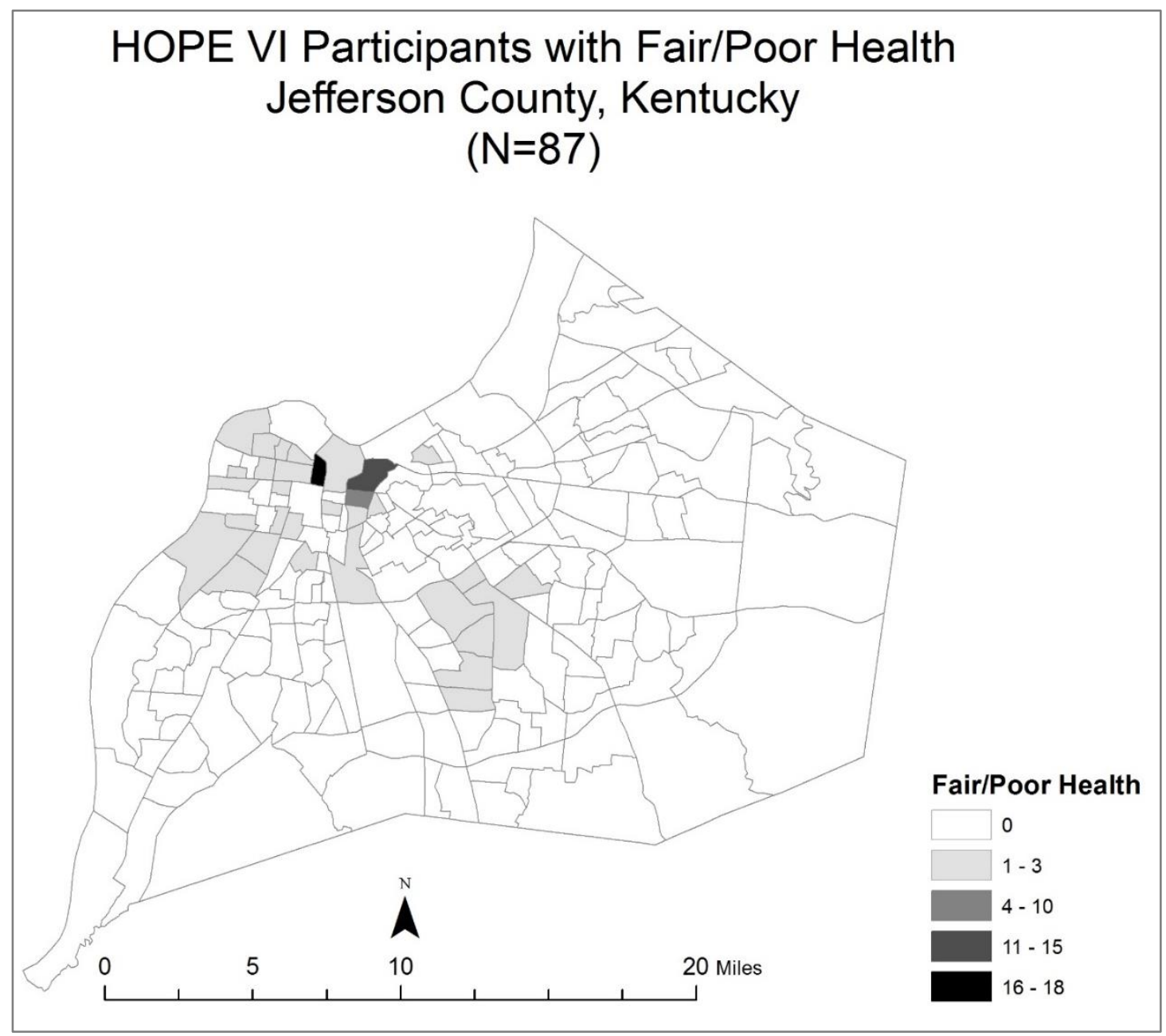

Figure 12. Participants with Perceived Fair or Poor Health 
There were 32 CTs with 87 participants who perceived their health as fair/poor. There were 16 CTs with one person, 8 CTs with two persons, 5 CTs with three persons, while the last 3 CTs had 9, 13, and respectively 18 persons with fair/poor health. In addition, the distribution of the 87 residents is presented in Figure 13 together with the location of health clinics (red cross) and of hospitals (blue triangle), to illustrate their proximity to healthcare facilities. The majority of participants with fair/poor health resided in the public housing located in the downtown areas.

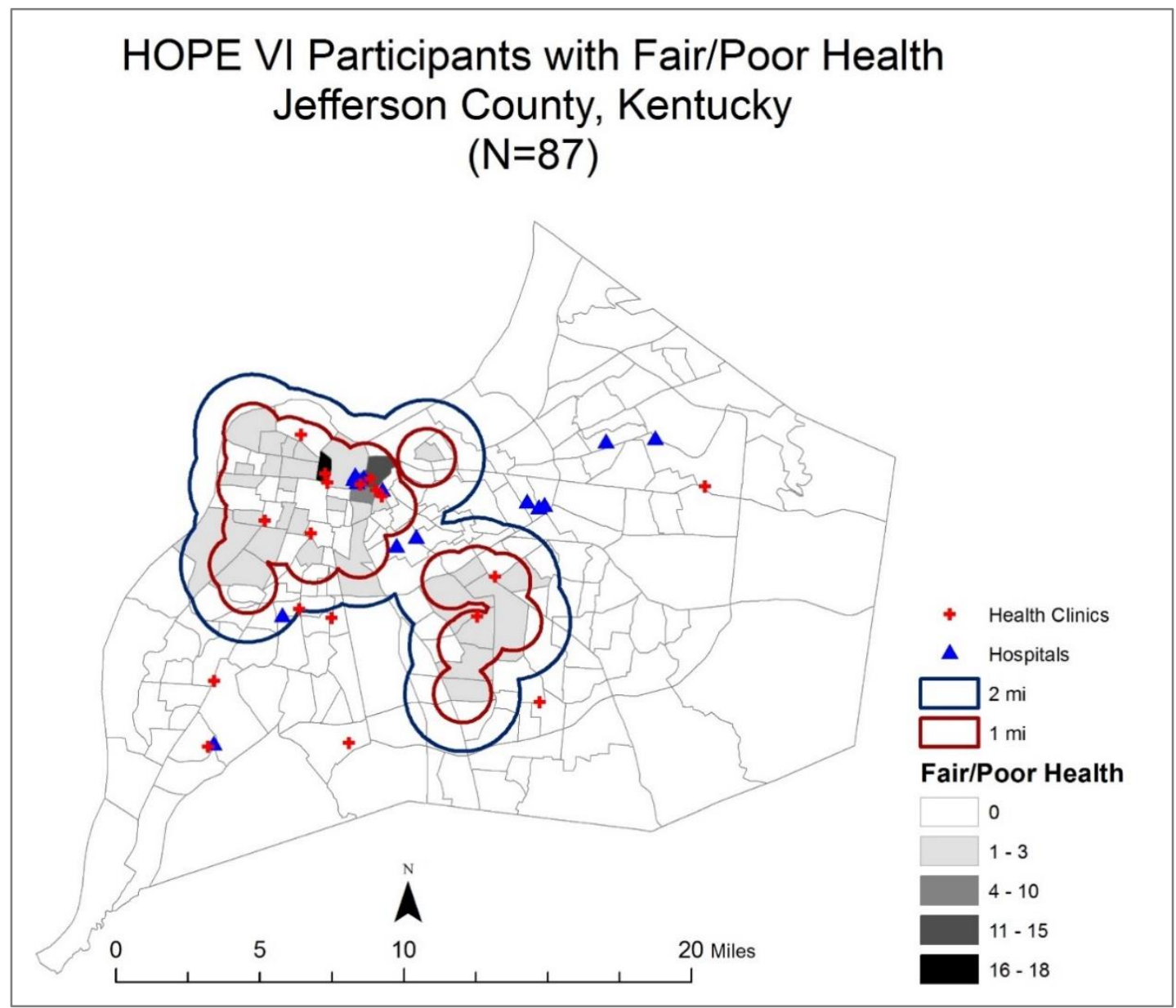

Figure 13. Perceived Fair or Poor Health: Proximity to Healthcare Facilities 


\section{CHAPTER V \\ DISCUSSION AND CONCLUSIONS}

The FIT return rate in this study exceeded the return rates reported by previous studies. The higher return rate may be due to using a different strategy to recruit participants. In this study, randomly selected individuals from a population of ageeligible, low socioeconomic status, African American population, at high risk for CRC, were paid a home visit. In comparison, the other studies recruited participants through outreach in the community or at the local clinics. Home visitation was an opportunity to establish a more personable relationship, to earn participants' trust, and set the foundation for a sustainable relationship that led to higher rates of follow-up. However, because all of the participants were very low income, it was difficult to estimate the impact of the home visitation versus the impact of the financial incentives on the participation rates. It is reasonable to assume that financial compensation played an important role in increasing participation rates, along with the prepaid return envelope provided with the FIT kit during the home visit.

Another reason for the high rate of FIT kit return may have been the non-invasive nature of this study, along with the free, valuable health information they received. Moreover, the results were confidential and there was no pressure to follow-up with a colonoscopy. It is noteworthy that, while the follow-up study on the completed colonoscopies is forthcoming, all of the participants with a FIT reactive result stated that 
they will schedule a colonoscopy. In fact, a few of these residents reached out for help to find a chaperone and transportation for the procedure, and they were linked to free community resources.

About half of the individuals who participated in the study, majority of age 50 or older, had a colonoscopy or sigmoidoscopy 12 months or more prior to this study. This rate is similar to the rate reported by other studies (Sineshaw, Robbins, and Jemal 2014) for the general African American population. This means that the CRC screening rates in very low-income African American population, with health insurance and a regular healthcare provider, are not significantly different than the CRC screening rates in the general African American population. Nevertheless, low and very low income populations residing in subsidized housing are less likely to visit a healthcare provider, in spite of their free access to healthcare and to a regular healthcare provider, and regardless of their proximity to healthcare facilities. It is noteworthy that the over $95 \%$ rate of insured individuals is a result of Kentucky's expansion of Medicaid, which offers full coverage to all individuals with incomes $133 \%$ above the federal poverty level.

Another finding was that younger, employed participants were less likely to have had a prior CRC screening, in spite of having health insurance and a regular healthcare provider. Within this group, the participants with family history of cancer were more likely to have had a prior CRC screening. In spite of the lower participation among employed residents and among those who were relocated in scattered housing or in subsidized rental units, these two groups may be the ones who would benefit the most from using a home visit outreach strategy and/or from screening with prepaid mailing of FIT kits. 
Individuals who resided in scattered public housing or in subsidized rental units appear to be less likely to return the FIT kit. This is the opposite behavior of what was expected based on the literature on HOPE VI programs (Curley 2010). The theory of social capital suggests that people who reside in mixed-income communities increase their social capital, and they are likely to copy the "better" behaviors of their neighbors. The theory may be supported by the behaviors of individuals who reside in larger public housing, but it does not seem to be supported by the behaviors of individuals residing in slightly more mixed-income communities. It is noteworthy, that this finding was only marginally significant, at $90 \%$ confidence level.

The key finding of this study was that an individual's perception of his or her health status is the main predictor of FIT kit return and of CRC screening behavior. No matter the place of residence, age or employment status, participants who perceived their health as less than good were more likely to return the FIT kits, and were more likely to have had a prior CRC screening. This finding shows that screening behavior is very much like medical care seeking behavior. Therefore, Andersen's model, which prescribes that individual perception of a health need is the key factor for seeking medical care, and was an appropriate theoretical model for this study.

Finally, the standard outreach for CRC screening generally occurs in healthcare facilities (Myers et al. 2007). Community outreach and recruitment of patients in healthcare settings was found to be successful in many populations, but this study showed that home visitation can be a successful strategy to increase screening for colorectal cancer in high risk populations such as low and very low income communities of African Americans. To conclude, CRC screening within urban clusters of high poverty areas may 
be more successful if conducted by community health advocates, via home visits, so that participants receive more individualized attention. Close proximity to health care facilities, free health insurance, and a regular healthcare provider do not guarantee that they get the healthcare they need. However, the hypothesis of this thesis research, that the socioeconomic level of the area of residence has no bearing on individual health seeking behavior after controlling for individual characteristics, seems to be confirmed.

\section{$\underline{\text { Limitations }}$}

The findings of this study have several limitations. First, they are limited by the use of a small sample, given that this was a pilot study. Second, even though the sample was randomly selected, it would be difficult to generalize the results to other urban public housing populations using the pilot sample; there is a need for a control group, a sample of public housing residents who were not part of the HOPE VI program. Third, the researchers collected only a limited number of variables, which did not provide sufficient information about the participants to explain the differences in their screening behaviors. The public housing population is highly homogenous in terms of race and income; over 90\% are African American and all of them have very low incomes. They are fairly homogenous in terms of health too, because many times their housing subsidy is due to poor physical or mental health or due to some type of disability.

Another study limitation is that senior housing developments and the other public housing developments for families with children and younger single people, such as Park Hill or Beecher Terrace, were included in the same category. Thus, it is reasonable to 
assume that many factors that could have differentiated between different groups of public housing residents were not included in the survey. Future studies should include more extensive measurements and larger samples that would allow estimations of the effect of age, of the place of residence, and of the employment status on screening behavior. Finally, the differences between the neighborhoods of residence were not significant and thus a multilevel model could not be developed. Similarly, while this is a "good" limitation to have, the fact that almost all of the participants have health insurance and a regular medical provider made it impossible to test the differences in screening behaviors made by access to healthcare. 


\section{REFERENCES}

Andersen, R. M. 1995. Revisiting the behavioral model and access to medical care: Does it matter? Journal of Health Social Behavior 36 (1): 1-10.

Beyer, K. M., Y. Zhou, K. Matthews, K. Hoormann, A. Bemanian, P. W. Laud, and A. B. Nattinger. 2016. Breast and colorectal cancer survival disparities in southeastern Wisconsin. Wisconsin Medical Journal 115 (1): 17-21.

Bolen, J., M. Adams, and D. Shenson. 2007. Routine preventive services for older women: A composite measure highlights gaps in delivery. Journal of Womens Health (Larchmt) 16 (5): 583-93.

Brenner, A. T., S. Gupta, L. K. Ko, N. Janz, and J. M. Inadomi. 2016. Development of a practical model for targeting patient decision support interventions to promote colorectal cancer screening in vulnerable populations. Journal of the Health Care for the Poor and Underserved 27 (2): 465-78.

Brenner, A. T., L. K. Ko, N. Janz, S. Gupta, and J. Inadomi. 2015. Race/ethnicity and primary language: Health beliefs about colorectal cancer screening in a diverse, low-income population. Journal of the Health Care for the Poor and Underserved 26 (3): 824-38.

Cole, A. M., J. E. Jackson, and M. Doescher. 2012. Urban-rural disparities in colorectal cancer screening: Cross-sectional analysis of 1998-2005 data from the Centers for Disease Control's Behavioral Risk Factor Surveillance Study. Cancer Medicine 1 (3): 350-6.

Cooper, G. S., Z. Yuan, C. S. Landefeld, J. F. Johanson, and A. A. Rimm. 1995. A national population-based study of incidence of colorectal cancer and age. Implications for screening in older Americans. Cancer 75 (3): 775-81.

Cress, R. D., C. Morris, G. L. Ellison, and M. T. Goodman. 2006. Secular changes in colorectal cancer incidence by subsite, stage at diagnosis, and race/ethnicity, 1992-2001. Cancer 107 (5 Suppl): 1142-52.

Curley, A. M. 2010. Relocating the poor: Social capital and neighborhood resources. Journal of Urban Affairs 32 (1): 79-103. 
Centers for Disease Control and Prevention. 2016. Available at https://nccd.cdc.gov/uscs/ toptencancers.aspx (Last accessed 7 December 2016)

Daly, J. M., B. T. Levy, M. L. Merchant, and J. Wilbur. 2010. Mailed fecalimmunochemical test for colon cancer screening. Journal of Community Health 35 (3): 235-9.

Daly, J. M., B. T. Levy, C. A. Moss, and C. P. Bay. 2015. System strategies for colorectal cancer screening at Federally Qualified Health Centers. American Journal of Public Health 105 (1): 212-219.

Davis, S. N., H. Thompson, Y. E. Gutierrez, S. G. Boateng, and L. Jandorf. 2002. \#6-S breast cancer fatalism: Ethnic differences and association with cancer screening. Annals of Epidemiology 12 (7): 491-492.

Doubeni, C. A., A. O. Laiyemo, J. M. Major, M. Schootman, M. Lian, Y. Park, B. I. Graubard, A. R. Hollenbeck, and R. Sinha. 2012. Socioeconomic status and the risk of colorectal cancer: An analysis of more than a half million adults in the National Institutes of Health-AARP Diet and Health Study. Cancer 118 (14): 3636-44.

Doubeni, C. A., A. O. Laiyemo, G. Reed, T. S. Field, and R. H. Fletcher. 2009. Socioeconomic and racial patterns of colorectal cancer screening among Medicare enrollees in 2000 to 2005. Cancer Epidemiology Biomarkers Prevention 18 (8): 2170-5.

Doubeni, C. A., M. Schootman, J. M. Major, R. A. Stone, A. O. Laiyemo, Y. Park, M. Lian, L. Messer, B. I. Graubard, R. Sinha, A. R. Hollenbeck, and A. Schatzkin. 2012. Health status, neighborhood socioeconomic context, and premature mortality in the United States: The National Institutes of Health-AARP Diet and Health Study. American Journal of Public Health 102 (4): 680-8.

Enewold, L., J. Zhou, K. A. McGlynn, S. S. Devesa, C. D. Shriver, J. F. Potter, S. H. Zahm, and K. Zhu. 2012. Racial variation in tumor stage at diagnosis among Department of Defense beneficiaries. Cancer 118 (5): 1397-403.

Escoffery, C., M. E. Fernandez, S. W. Vernon, S. Liang, A. E. Maxwell, J. D. Allen, A. Dwyer, P. A. Hannon, M. Kohn, and A. DeGroff. 2015. Patient navigation in a colorectal cancer screening program. Journal of Public Health Management Practice 21 (5): 433-40.

Espey, D. K., X. C. Wu, J. Swan, C. Wiggins, M. A. Jim, E. Ward, P. A. Wingo, H. L. Howe, L. A. Ries, B. A. Miller, A. Jemal, F. Ahmed, N. Cobb, J. S. Kaur, and B. K. Edwards. 2007. Annual report to the nation on the status of cancer, 1975-2004, featuring cancer in American Indians and Alaska Natives. Cancer 110 (10): 211952. 
Faruque, F. S., X. Zhang, E. N. Nichols, D. L. Bradley, R. Reeves-Darby, V. ReevesDarby, and R. J. Duhe. 2015. The impact of preventive screening resource distribution on geographic and population-based disparities in colorectal cancer in Mississippi. BioMed Central Resident Notes 8: 423.

Green, B. B., and G. D. Coronado. 2014. "BeneFITs" to increase colorectal cancer screening in priority populations. Journal of the American Medical Association Internal Medicine 174 (8): 1242-3.

Hall, M. J., K. Ruth, and V. N. Giri. 2012. Rates and predictors of colorectal cancer screening by race among motivated men participating in a prostate cancer risk assessment program. Cancer 118 (2): 478-84.

Hao, Y., A. Jemal, X. Zhang, and E. M. Ward. 2009. Trends in colorectal cancer incidence rates by age, race/ethnicity, and indices of access to medical care, 19952004 (United States). Cancer Causes Control 20 (10): 1855-63.

Hassan, M. O., Z. Arthurs, V. Y. Sohn, and S. R. Steele. 2009. Race does not impact colorectal cancer treatment or outcomes with equal access. American Journal of Surgery 197 (4): 485-90.

Hayward, E., C. Ibe, J. H. Young, K. Potti, P. Jones, 3rd, C. E. Pollack, and K. A. Gudzune. 2015. Linking social and built environmental factors to the health of public housing residents: A focus group study. BioMed Central Public Health 15: 351.

Hines, R. B., and T. W. Markossian. 2012. Differences in late-stage diagnosis, treatment, and colorectal cancer-related death between rural and urban African Americans and whites in Georgia. Journal of Rural Health 28 (3): 296-305.

Jemal, A., R. L. Siegel, J. Ma, F. Islami, C. DeSantis, A. Goding Sauer, E. P. Simard, and E. M. Ward. 2015. Inequalities in premature death from colorectal cancer by state. Journal of Clinical Oncology 33 (8): 829-35.

Laiyemo, A. O., C. Doubeni, P. F. Pinsky, V. P. Doria-Rose, R. Bresalier, L. E. Lamerato, E. D. Crawford, P. Kvale, M. Fouad, T. Hickey, T. Riley, J. Weissfeld, R. E. Schoen, P. M. Marcus, P. C. Prorok, and C. D. Berg. 2010. Race and colorectal cancer disparities: Health-care utilization vs different cancer susceptibilities. Journal of National Cancer Institute 102 (8): 538-46.

Manjarrez, C.A., Popkin, S.J. and Guernsey, E. 2007. Poor health: Adding insult to injury for HOPE VI families. The Urban Institute, Metropolitan Housing and Communities Center, Brief No. 5, June 2007. Available at: http://www.urban.org/UploadedPDF/311489_HOPEVI_Health.pdf 
McLafferty, S., and F. Wang. 2009. Rural reversal? Rural-urban disparities in late-stage cancer risk in Illinois. Cancer 115 (12): 2755-64.

Monson, J. R., C. P. Probst, S. D. Wexner, F. H. Remzi, J. W. Fleshman, J. GarciaAguilar, G. J. Chang, and D. W. Dietz. 2014. Failure of evidence-based cancer care in the United States: The association between rectal cancer treatment, cancer center volume, and geography. Annals of Surgery 260 (4): 625-31; discussion 631-2.

Myers, R. E., R. Sifri, T. Hyslop, M. Rosenthal, S. W. Vernon, J. Cocroft, T. Wolf, J. Andrel, and R. Wender. 2007. A randomized controlled trial of the impact of targeted and tailored interventions on colorectal cancer screening. Cancer 110 (9): 2083-91.

Oort, F. A., J. S. Terhaar Sive Droste, R. W. Van Der Hulst, H. A. Van Heukelem, R. J. Loffeld, I. C. Wesdorp, R. L. Van Wanrooij, L. De Baaij, E. R. Mutsaers, S. van der Reijt, V. M. Coupe, J. Berkhof, A. A. Bouman, G. A. Meijer, and C. J. Mulder. 2010. Colonoscopy-controlled intra-individual comparisons to screen relevant neoplasia: Faecal immunochemical test vs. guaiac-based faecal occult blood test. Alimentary Pharmacology and Therapeutics 31 (3): 432-9.

Paskett, E. D., J. L. Fisher, E. J. Lengerich, N. E. Schoenberg, S. K. Kennedy, M. E. Conn, K. A. Roberto, S. K. Dwyer, D. Fickle, and M. Dignan. 2011. Disparities in underserved white populations: The case of cancer-related disparities in Appalachia. Oncologist 16 (8): 1072-81.

Perdue, D. G., D. Haverkamp, C. Perkins, C. M. Daley, and E. Provost. 2014. Geographic variation in colorectal cancer incidence and mortality, age of onset, and stage at diagnosis among American Indian and Alaska Native people, 1990-2009. American Journal of Public Health 104 Suppl 3: S404-14.

Pollack, C. E., H. D. Green, Jr., D. P. Kennedy, B. A. Griffin, A. Kennedy-Hendricks, S. Burkhauser, and H. Schwartz. 2014. The impact of public housing on social networks: A natural experiment. American Journal of Public Health 104 (9): 1642-9.

Sabounchi, S., S. Keihanian, and B. S. Anand. 2012. Impact of race on colorectal cancer. Clinical Colorectal Cancer 11 (1): 66-70.

Schenck, A. P., S. C. Peacock, C. N. Klabunde, P. Lapin, J. F. Coan, and M. L. Brown. 2009. Trends in colorectal cancer test use in the medicare population, 1998-2005. American Journal for Preventive Medicine 37 (1): 1-7.

Shokar, N. K., T. Byrd, D. R. Lairson, R. Salaiz, J. Kim, J. Calderon-Mora, N. Nguyen, and M. Ortiz. 2015. Against Colorectal Cancer in Our Neighborhoods, a Community-based colorectal cancer screening program targeting low-income 
hispanics: Program development and costs. Health Promotion Practice 16 (5): $656-66$.

Sineshaw, H. M., A. S. Robbins, and A. Jemal. 2014. Disparities in survival improvement for metastatic colorectal cancer by race/ethnicity and age in the United States. Cancer Causes Control 25 (4): 419-23.

Steele, C. B., C. J. Cardinez, L. C. Richardson, L. Tom-Orme, and K. M. Shaw. 2008. Surveillance for health behaviors of American Indians and Alaska Nativesfindings from the behavioral risk factor surveillance system, 2000-2006. Cancer 113 (5 Suppl): 1131-41.

Suzuki, R., P. M. Wallace, and E. Small. 2015. Race, health-related quality of life and colorectal cancer screening rates in the National Health Interview Survey. American Journal of Health Behavior 39 (1): 132-9.

Tawk, R., A. Abner, A. Ashford, and C. P. Brown. 2015. Differences in colorectal cancer outcomes by race and insurance. International Journal of Environmental Research and Public Health 13 (1):ijerph13010048.

Theuer, C. P., T. H. Taylor, W. R. Brewster, and H. Anton-Culver. 2006. Gender and race/ethnicity affect the cost-effectiveness of colorectal cancer screening. Journal of National Medical Association 98 (1): 51-7.

Towne, S. D., Jr., M. L. Smith, S. Ahn, M. Altpeter, B. Belza, K. P. Kulinski, and M. G. Ory. 2014. National dissemination of multiple evidence-based disease prevention programs: Reach to vulnerable older adults. Front Public Health 2: 156.

Towne, S. D., Jr., M. L. Smith, and M. G. Ory. 2014. Geographic variations in access and utilization of cancer screening services: Examining disparities among American Indian and Alaska Native Elders. International Journal of Health Geography 13:18.

Wheeler, S. B., T. M. Kuo, R. K. Goyal, A. M. Meyer, K. Hassmiller Lich, E. M. Gillen, S. Tyree, C. L. Lewis, T. M. Crutchfield, C. E. Martens, F. Tangka, L. C. Richardson, and M. P. Pignone. 2014. Regional variation in colorectal cancer testing and geographic availability of care in a publicly insured population. Health Place 29: 114-23.

Winterich, J. A., S. A. Quandt, J. G. Grzywacz, P. Clark, M. Dignan, J. H. Stewart, and T. A. Arcury. 2011. Men's knowledge and beliefs about colorectal cancer and 3 screenings: Education, race, and screening status. American Journal of Health Behavior 35 (5): 525-34. 


\section{APPENDICES}

\section{Table A1}

\section{$\underline{\text { Selected CRC Studies }}$}

\begin{tabular}{|c|c|c|c|c|}
\hline Article & Setting & Data Sources & Cases & Focus \\
\hline $\begin{array}{l}\text { (Beyer et al. } \\
\text { 2016) }\end{array}$ & $\begin{array}{l}\text { SE } \\
\text { Wisconsin }\end{array}$ & $\begin{array}{l}\text { Wisconsin } \\
\text { Cancer } \\
\text { Reporting } \\
\text { System (WCRS) }\end{array}$ & $\begin{array}{l}2002-2011 \\
\text { breast }(\mathrm{n}= \\
11,411) \text { or } \\
\text { colorectal } \\
(\mathrm{n}=7286)\end{array}$ & $\begin{array}{l}\text { Focuses on disparities in } \\
\text { breast and CRC survival in } \\
\text { SE WI to provide } \\
\text { actionable evidence to } \\
\text { guide future cancer control } \\
\text { efforts in the region. }\end{array}$ \\
\hline $\begin{array}{l}\text { (Bolen, } \\
\text { Adams, and } \\
\text { Shenson } \\
\text { 2007) }\end{array}$ & $\begin{array}{l}\text { DC and } 49 \\
\text { states, except } \\
\text { HI }\end{array}$ & $\begin{array}{l}\text { Data from the } \\
2004 \\
\text { (BRFSS) }\end{array}$ & $\mathrm{N}=91,156$ & $\begin{array}{l}\text { Used a composite measure } \\
\text { to examine the delivery of } \\
\text { routine clinical preventive } \\
\text { services to women ages } 50 \text { - } \\
64 \& 65+(2004) \text {. }\end{array}$ \\
\hline $\begin{array}{l}\text { (Brenner et } \\
\text { al. 2015) }\end{array}$ & $\begin{array}{l}\text { San } \\
\text { Francisco }\end{array}$ & $\begin{array}{l}\text { Colon Cancer } \\
\text { Screening } \\
\text { Adherence Study }\end{array}$ & $\mathrm{N}=933$ & $\begin{array}{l}\text { Explore whether health } \\
\text { belief model (HBM) } \\
\text { constructs pertaining to } \\
\text { CRC screening differ by } \\
\text { race/ethnicity and primary } \\
\text { language. }\end{array}$ \\
\hline $\begin{array}{l}\text { (Brenner et } \\
\text { al. 2016) }\end{array}$ & $\begin{array}{l}\text { San } \\
\text { Francisco }\end{array}$ & $\begin{array}{l}\text { 2007-2008 CRC } \\
\text { Adherence Study }\end{array}$ & $\mathrm{N}=997$ & $\begin{array}{l}\text { To develop a practical } \\
\text { model for predicting } \\
\text { probability of (CRC) } \\
\text { screening completion in a } \\
\text { diverse safety-net } \\
\text { population and a } \\
\text { framework for targeting } \\
\text { screening promotion } \\
\text { interventions. }\end{array}$ \\
\hline $\begin{array}{l}\text { (Cooper et } \\
\text { al. 1995) }\end{array}$ & U.S. & $\begin{array}{l}1987 \\
\text { Medicare } \\
\text { Provider } \\
\text { Analysis \& } \\
\text { Review } \\
\end{array}$ & $\mathrm{N}=75,266$ & $\begin{array}{l}\text { Examined the anatomic } \\
\text { distribution of colorectal } \\
\text { tumors by age, sex, and } \\
\text { race in Medicare population } \\
\text { ( } 65 \text { and older). }\end{array}$ \\
\hline $\begin{array}{l}\text { (Cress et al. } \\
2006)\end{array}$ & & $\begin{array}{l}1992 \text { and } 2001 \\
\text { NCI (SEER) }\end{array}$ & $\begin{array}{l}M=95,539 \& \\
F=93,329\end{array}$ & $\begin{array}{l}\text { Focus on patterns of CRC } \\
\text { incidence by gender, } \\
\text { race/ethnicity, and area of } \\
\text { residence }\end{array}$ \\
\hline
\end{tabular}




\begin{tabular}{|c|c|c|c|c|}
\hline $\begin{array}{l}\text { (Daly et al. } \\
2010)\end{array}$ & Iowa & $\begin{array}{l}\text { Conducted in a } \\
\text { tertiary } \\
\text { Midwestern } \\
\text { medical Center's } \\
\text { family medicine } \\
\text { clinic. }\end{array}$ & $\begin{array}{l}350 \text { potential } \\
\text { subjects } \\
\text { randomly } \\
\text { selected from } \\
1,564 \\
\text { patients. }\end{array}$ & $\begin{array}{l}\text { Regular patients of a clinic, } \\
\text { ages 50-64 years, not up- } \\
\text { to-date with CRC screening } \\
\text { will complete the at-home } \\
\text { (FIT) test if it is mailed to } \\
\text { them. }\end{array}$ \\
\hline $\begin{array}{l}\text { (Doubeni, } \\
\text { Laiyemo, et } \\
\text { al. 2012) }\end{array}$ & $\begin{array}{l}\text { CA, FL, LA, } \\
\text { NJ, NC, PA } \\
\text { and } 2 \text { metro } \\
\text { areas } \\
\text { (Atlanta, GA } \\
\text { and Detroit, } \\
\text { MI) }\end{array}$ & $\begin{array}{l}\text { NIH-AARP Diet } \\
\text { and Health } \\
\text { Study (NIH- } \\
\text { AARP study). } \\
\text { 1995-1996. }\end{array}$ & $\begin{array}{l}506,488 \\
\text { participants } \\
\text { analyzed }\end{array}$ & $\begin{array}{l}\text { This study examined the } \\
\text { relationship between both } \\
\text { individual and area-level } \\
\text { SES and CRC incidence, } \\
\text { overall and by tumor } \\
\text { location. }\end{array}$ \\
\hline $\begin{array}{l}\text { (Doubeni, } \\
\text { Schootman, } \\
\text { et al. 2012) }\end{array}$ & $\begin{array}{l}\text { CA, FL, LA, } \\
\text { NJ, NC, PA } \\
\text { and (Atlanta, } \\
\text { GA and } \\
\text { Detroit, MI) }\end{array}$ & $\begin{array}{l}\text { NIH-AARP Diet } \\
\text { and Health } \\
\text { Study. } 1995- \\
1996 \& 2004 \text { to } \\
2006\end{array}$ & $\begin{array}{l}567,169 \\
\text { AARP } \\
\text { members } \\
\text { aged } 50 \text { to } 71 \\
\text { years }\end{array}$ & $\begin{array}{l}\text { Neighborhood } \\
\text { socioeconomic inequalities } \\
\text { lead to large disparities in } \\
\text { risk of premature mortality } \\
\text { among healthy U.S. adults } \\
\text { but not among those in poor } \\
\text { health. }\end{array}$ \\
\hline $\begin{array}{l}\text { (Enewold et } \\
\text { al. 2012) }\end{array}$ & $\begin{array}{l}9 \text { SEERs } \\
\text { (CT, IA, NM, } \\
\text { UT, HI, } \\
\text { Detroit, San } \\
\text { Francisco- } \\
\text { Oakland, } \\
\text { Atlanta, } \\
\text { Seattle- } \\
\text { Puget) } \\
\end{array}$ & $\begin{array}{l}\text { Department of } \\
\text { Defense } \\
\text { Automated } \\
\text { Cancer Tumor } \\
\text { Registry from } \\
1990 \text { to } 2003\end{array}$ & & $\begin{array}{l}\text { To determine whether } \\
\text { tumor stage differed } \\
\text { between whites and blacks } \\
\text { with breast, cervical, } \\
\text { colorectal, and prostate } \\
\text { cancers, which have } \\
\text { effective screening } \\
\text { regimens. }\end{array}$ \\
\hline $\begin{array}{l}\text { (Escoffery } \\
\text { et al. 2015) }\end{array}$ & $\begin{array}{l}25 \text { states and } \\
4 \text { tribal } \\
\text { organizations }\end{array}$ & $\begin{array}{l}\text { November to } \\
\text { December } 2011\end{array}$ & & $\begin{array}{l}\text { The purpose of this study } \\
\text { was to characterize patient } \\
\text { navigation (PN) programs } \\
\text { for screening provision and } \\
\text { promotion for the first } 1 \text { to } \\
2 \text { years of program funding. }\end{array}$ \\
\hline $\begin{array}{l}\text { (Hall, Ruth, } \\
\text { and Giri } \\
\text { 2012) }\end{array}$ & $\begin{array}{l}\text { Philadelphia } \\
\text { area }\end{array}$ & $\begin{array}{l}\text { Fox Chase } \\
\text { Cancer Center }\end{array}$ & $\mathrm{N}=812$ & $\begin{array}{l}\text { Assessment of disparities in } \\
\text { uptake of CRC screening } \\
\text { among men participating in } \\
\text { a high-risk prostate cancer } \\
\text { clinic. }\end{array}$ \\
\hline $\begin{array}{l}\text { (Hao et al. } \\
2009 \text { ) }\end{array}$ & $\begin{array}{l}18 \text { states, } \\
\text { Detroit } \\
\text { metro, CA, } \\
\text { CO, CT, FL, } \\
\text { HI, ID, IL, } \\
\text { IA, KY, LA, } \\
\text { ME, NE, NJ, } \\
\text { NY, RI, TX, } \\
\text { UT, WA. }\end{array}$ & $\begin{array}{l}1995 \text { to } 2004 \\
\text { Behavioral Risk } \\
\text { Factor } \\
\text { Surveillance } \\
\text { System (BRFSS) }\end{array}$ & $\mathrm{N}=336,819$ & $\begin{array}{l}\text { Individuals residing in } \\
\text { poorer communities with } \\
\text { lower access to medical } \\
\text { care did not experience the } \\
\text { reduction in CRC incidence } \\
\text { rates seen in more affluent } \\
\text { communities; disparities } \\
\text { may be related to healthcare } \\
\text { access barriers to CRC } \\
\text { endoscopic screening. }\end{array}$ \\
\hline
\end{tabular}




\begin{tabular}{|c|c|c|c|c|}
\hline $\begin{array}{l}\text { (Hassan et } \\
\text { al. 2009) }\end{array}$ & Cannot find & $\begin{array}{l}\text { DOD tumor } \\
\text { registry } 01 / 1994 \\
\text { to } 01 / 2004\end{array}$ & $\mathrm{~N}=398$ & $\begin{array}{l}\text { Ethnicity is a factor for } \\
\text { disparate outcomes in CRC. }\end{array}$ \\
\hline $\begin{array}{l}\text { (Laiyemo et } \\
\text { al. 2010) }\end{array}$ & $\begin{array}{l}\text { AL, CO, MI, } \\
\text { HI, WI, MN, } \\
\text { PA, UT, MO, } \\
\text { DC. }\end{array}$ & $\begin{array}{l}\text { November } 1993 \\
\text { to July } 2001 \mathrm{NCI}\end{array}$ & $\mathrm{N}=60,572$ & $\begin{array}{l}\text { Disproportionately higher } \\
\text { incidence and mortality } \\
\text { from CRC among blacks } \\
\text { compared with whites } \\
\text { reflect differences in } \\
\text { health-care utilization or } \\
\text { CRC susceptibility. }\end{array}$ \\
\hline $\begin{array}{l}\text { (Sabounchi, } \\
\text { Keihanian, } \\
\text { and Anand } \\
\text { 2012) }\end{array}$ & US & $\begin{array}{l}1996 \text { to } 2010 \\
\text { Michael E. } \\
\text { DeBakey VA } \\
\text { Medical } \\
\text { Center in } \\
\text { Houston, TX }\end{array}$ & $\begin{array}{l}205 \text { White } \\
\text { and } \\
95 \text { Black }\end{array}$ & $\begin{array}{l}\text { Found no racial difference } \\
\text { in the Tx outcome of CRC } \\
\text { in VA patients; patients } \\
\text { with similar tx had similar } \\
\text { outcomes; severity of } \\
\text { disease at presentation and } \\
\text { the outcome of tx not } \\
\text { dependent on race. }\end{array}$ \\
\hline $\begin{array}{l}\text { (Shokar et } \\
\text { al. 2015) }\end{array}$ & $\begin{array}{l}\text { El Paso } \\
\text { County, } \\
\text { Texas }\end{array}$ & $\begin{array}{l}\text { Against } \\
\text { Colorectal } \\
\text { Cancer in Our } \\
\text { Neighborhoods } \\
\text { (ACCION) } \\
\text { Program }\end{array}$ & $\begin{array}{l}\text { population } \\
\text { screening; } \\
\text { about } 6,000 \\
\text { people }\end{array}$ & $\begin{array}{l}\text { Focus on development } \\
\text { processes and costs of a } \\
\text { health promotion program } \\
\text { for low-income Hispanics } \\
\text { to inform on planning and } \\
\text { developing new programs } \\
\text { to reduce disease burden }\end{array}$ \\
\hline $\begin{array}{l}\text { (Sineshaw, } \\
\text { Robbins, } \\
\text { and Jemal } \\
\text { 2014) }\end{array}$ & $\overline{\mathrm{US}}$ & $\begin{array}{l}1992-2009 \text { from } \\
13 \text { population- } \\
\text { based cancer } \\
\text { registries of NCI } \\
\text { SEER }\end{array}$ & $\begin{array}{l}\text { white } 34,642 \\
\text { Asian } 4,413 \\
\text { black } 6,369 \\
\text { Hispanic } \\
4,469\end{array}$ & $\begin{array}{l}\text { Non-Hispanic blacks, } \\
\text { Hispanics, and older } \\
\text { patients diagnosed with } \\
\text { metastatic CRC have not } \\
\text { equally benefitted from the } \\
\text { intro/dissem. of new Txs. }\end{array}$ \\
\hline $\begin{array}{l}\text { (Suzuki, } \\
\text { Wallace, } \\
\text { and Small } \\
\text { 2015) }\end{array}$ & US & NHIS 2010 & $\begin{array}{l}26,704 \\
\text { persons aged } \\
50 \text { to } 75 \\
\text { years }\end{array}$ & $\begin{array}{l}\text { Examine the association } \\
\text { between CRC screening } \\
\text { rates and health-related } \\
\text { quality of life (HRQOL). }\end{array}$ \\
\hline $\begin{array}{l}\text { (Theuer et } \\
\text { al. 2006) }\end{array}$ & California & $\begin{array}{l}\text { SEER Cancer } \\
\text { Incidence }\end{array}$ & 1992-1998 & $\begin{array}{l}\text { Influence of gender and } \\
\text { race/ethnicity on the cost- } \\
\text { effectiveness of rec. CRC } \\
\text { screening regimen. }\end{array}$ \\
\hline $\begin{array}{l}\text { (Winterich } \\
\text { et al. 2011) }\end{array}$ & US & $\begin{array}{l}\text { In-depth } \\
\text { interviews }\end{array}$ & $\begin{array}{l}65 \mathrm{AA} \text { and } \\
\mathrm{W} \text { men }\end{array}$ & $\begin{array}{l}\text { Compare how education, } \\
\text { race, and screening status } \\
\text { affected men's knowledge } \\
\text { about CRC and their views } \\
\text { of } 3 \text { screenings: the fecal } \\
\text { occult blood test (FOBT), } \\
\text { sigmoidoscopy, and } \\
\text { colonoscopy. }\end{array}$ \\
\hline
\end{tabular}




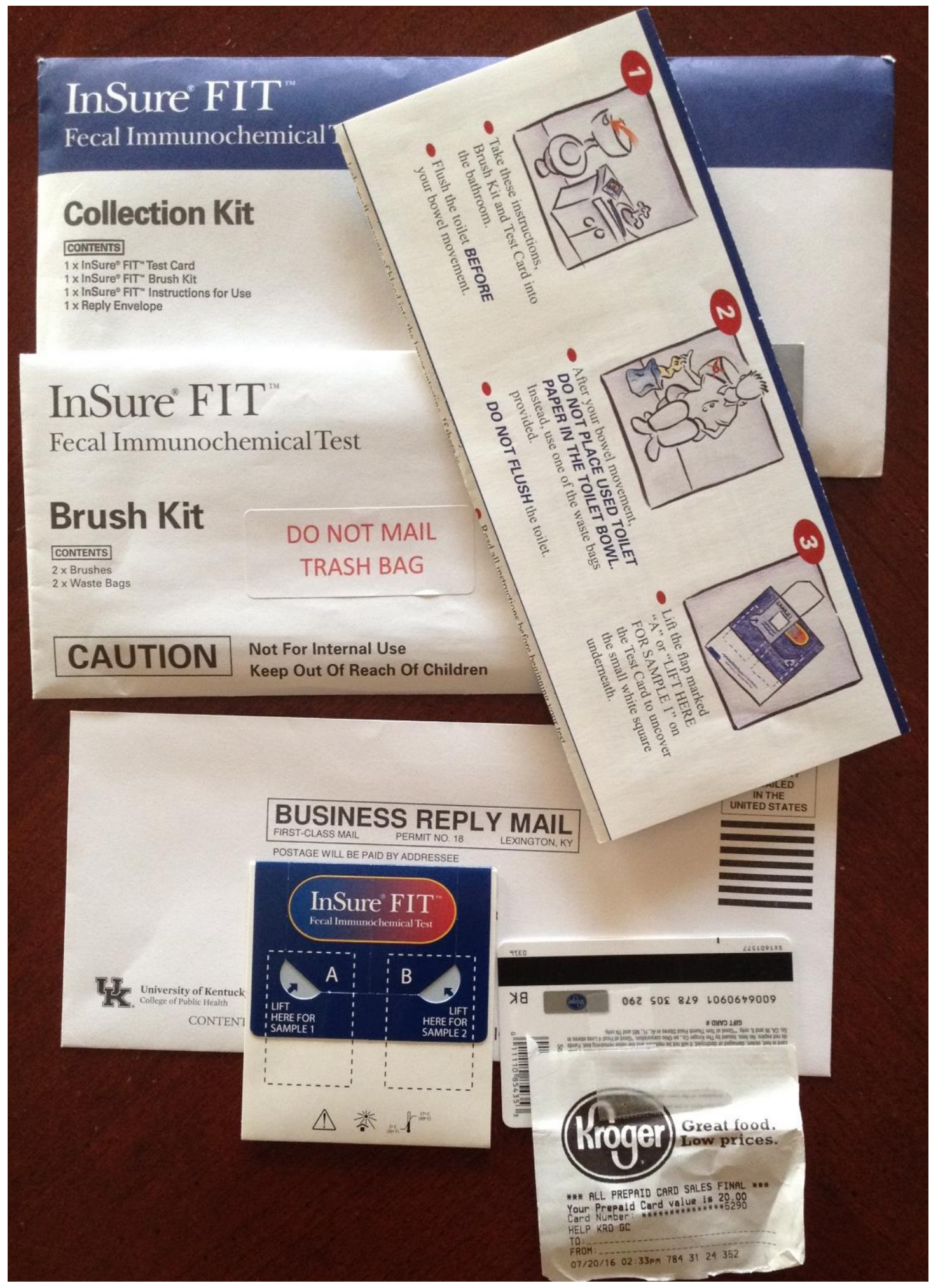

Figure A2. FIT Kit, UK Reply Envelope, \$20 Incentive- Kroger Gift Card 


\section{CURRICULUM VITAE}

NAME: Jeffrey Darren Stone

ADDRESS: 2201 Mahan Drive

Louisville, KY 40299

EDUCATION

\& TRAINING:

B.S., Geography

University of Louisville

2010-2012

A.S., Geography

Kentucky Community and Technical College System (KCTCS) 2008-2010

A.A.S., Graphic Design

Sullivan College of Technology and Design

2004-2006

AWARDS: Leonard Pardue Foundation Scholarship

2011-2012

KCTCS Academic Achievement

2010

KCTCS Dean's List

2009-2010

Silver ADDY Award (Kentucky)

2006

Sullivan College Dean's List

2004-2006

PROFESSIONAL SOCIETIES: American Evaluation Association

NATIONAL MEETING PRESENTATIONS:

Stone, R., Stone, J.D., Collins, T., Crosby, R. (2017) Colorectal cancer screening in Clarksdale and Sheppard Square HOPE VI population, Urban Affairs

Association, Annual meeting, Minneapolis, MN 